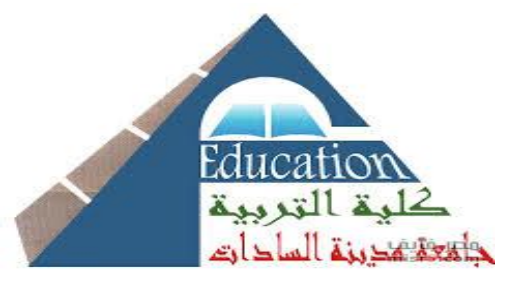

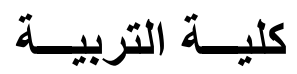

قسم علم النفس التربس

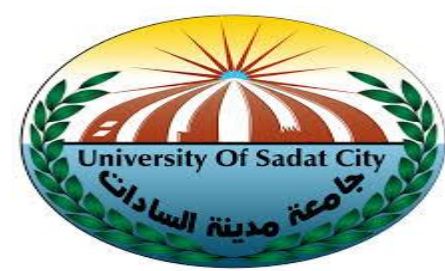

جامعـة مدينــة السادات

بحث مستخلص من رساله ماجستير بعنوان

فاعليه برنامج الإرشادي القائم على التفكير الايجابي لتخفيف قلى المستقبل لاى عينه من المعاقين بصريا في مرحله المراهقة

الاء يحيى زكي عبدالله

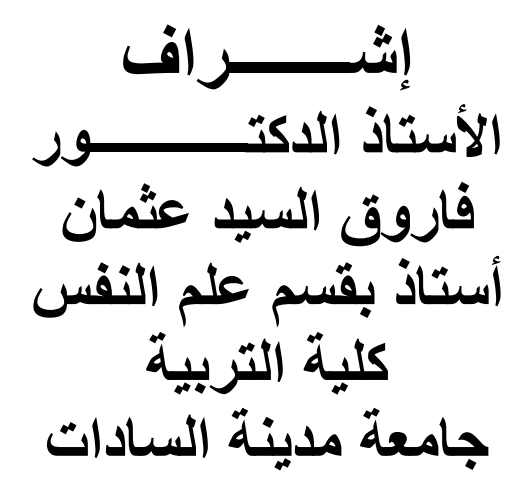


وتعد الإعاقة البصرية مشكلة من إحدى المشكلات التى يواجهها المراهق لكونها تحوله إلى طاقة بشرية معطلة تحتاج لمزيد من الإهتمام والرعاية، وتعتبر الاعاقة البصرية من المشكلات التى التى تهتم بها الدولة والكثير من علماء علم النفس والتربية أيضا لكونها ظاهرة متعددة الجوانب وتحتاج لجه كبير من القائمين على رعايتها وتأهيلها. من جانب آخر أكلات دراسات كثير من الباحثين أن قلق المستقبل يعد أحد المثكلات

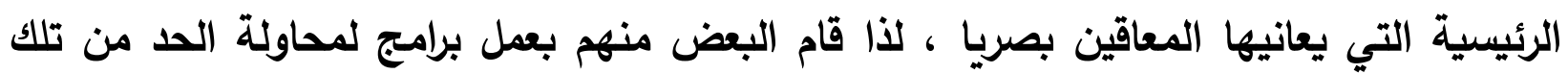
الأزمه لما يترتب عليها من آثار نفسية سيئة عند المعاق بصريا لئيا.

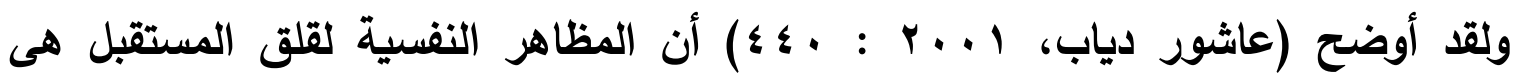
الثعور بالتوتر والأنزعاج لأبسط الأسباب والأحلام المزعجة واضطرابات النوم وإلخوف الثديد من

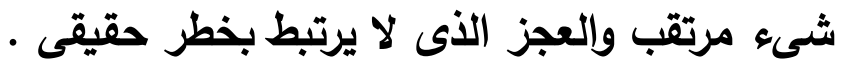
• مشكلة الدراسة : مشك

يمثل إرتفاع قلق المستقبل عند المراهق المعاق بصريا مشكلة نفسية واجتماعية كبيرة حيث أنها تعد مشكلة من مشكلات مرحله المراهقة، حيث أكلات بعض الدراسات مثل دراسة (محمد

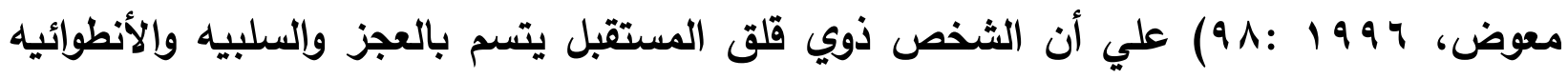
والثكك والحزن ونقص القدره علي مواجهه المستقبل.

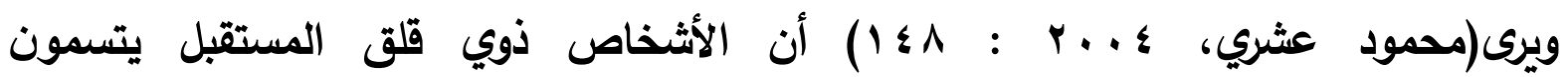

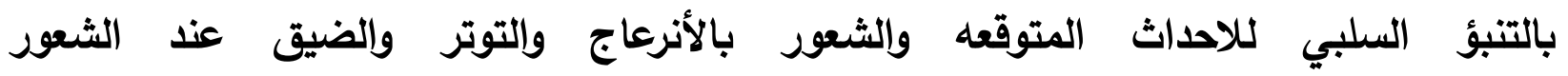
بها كما يتصفون ايصا بضعف القدره علي تحقيق الأمال والطموحات وعدم التركيز والثعور بأن الحياه غير جديره بالأهتمام مع الثعور بفقدان الأمن والطمأنينه تجاه المستقبل.

ولقد أكدت نتائج دراسة (Segerstrom,2005) وجود علاقه بين ارتفاع قلق

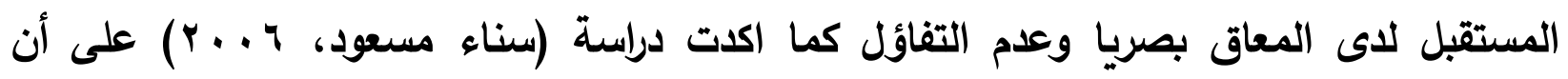

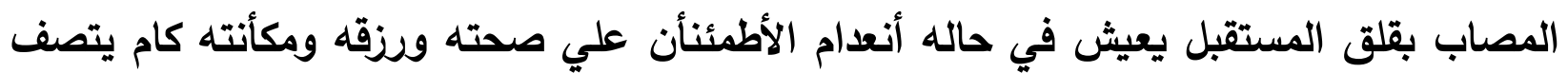
أيضا بالأعتماديه والعجز وإللاعقلانيه. 


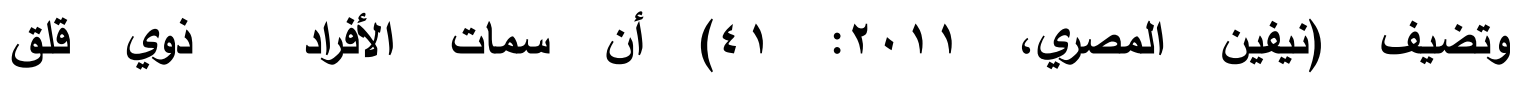

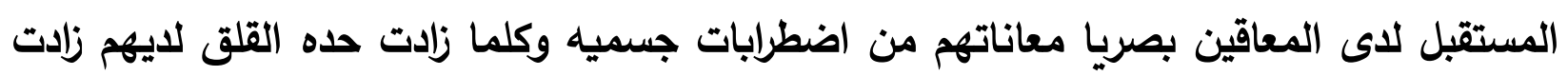
هذه الأعراض بالأضافه إلي عدم الإعتناء بصحته وقوتهم من اجل مواجهه المواقف الصعبه في

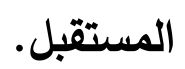

وأكلد أيضا نتائج دراسة (Behar,et al.,2012)علي وجود علاقه بين ارتفاع قلق المستقبل لاى المعاق بصريا والأكتئاب والتفكير السلبي المتكرر. وفي هذا الصدد اشارت نتائج دراسة (Gaber,et al.,2016) الي وجود علاقه بين مستوى الطموح والتفكير الناقد وقلق المستقبل لدى المعاق بصريا. ومما سبق يتضح أن المعاق بصريا مشغول جداً بالتفكير فى مستقبله ، وارتفاع قلق

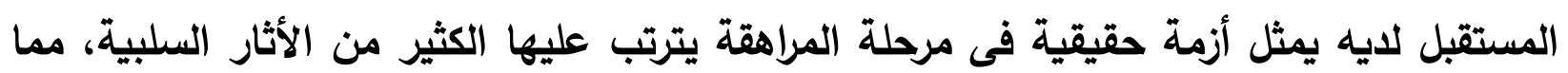
يتحتم علينا محاولة تخفيف قلق المستقبل عنده لكي يعود لتوافقه النفسى والأجتماعي. وعندما ننظر للتفكير الإيجابى نجد أنه من أنسب العلاجات المناسبة لهذه المشكلة وذلك لإعتماده على العديد من الإستراتيجيات المناسبة لتخفيف قلق المستقبل مثل" إستراتيجية حل

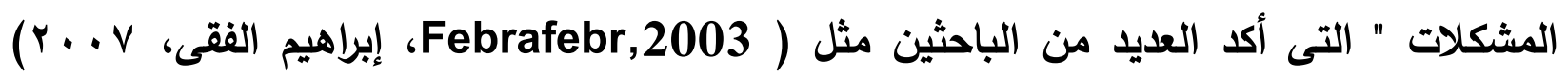
على فعاليتها فى جعل الفرد يركز إنتباهه على تحليل المواقف بطرق منطقية وهادئة ويتعلم منها ويعدل من أسلوبه ويتصرف بإيجابية حتى يتوصل لحلها، كما يعتمد التفكير الإيجابى على" إستراتيجية المثل الأعلى، وإستراتيجية الثخص الآخر إستراتيجية إعادة التعريف إستراتيجية البدائل

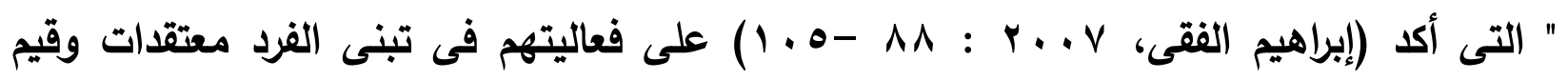

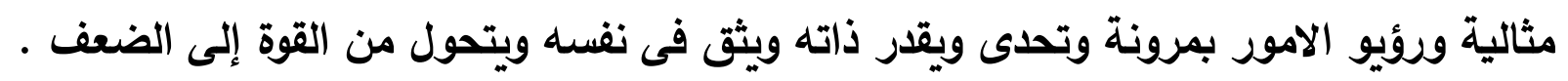
هذا وقد أكد العديد من الباحثين إرتباط قلق المستقبل بالتفكير الإيجابى والتوافق النفسى

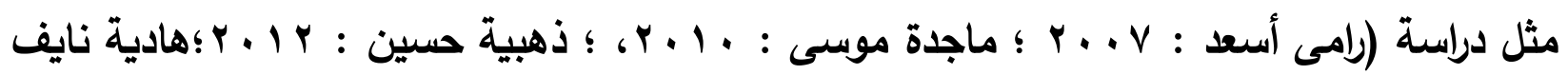

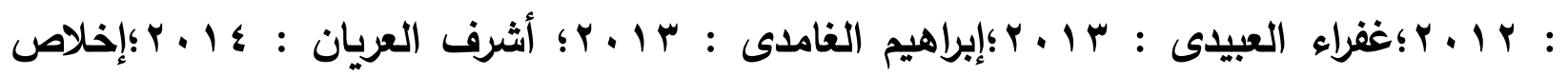

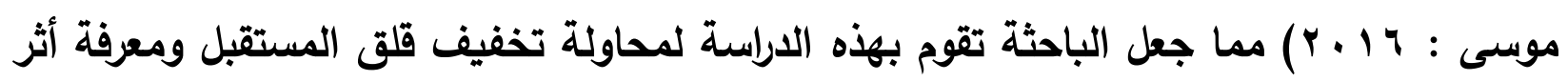
ذلك على المعاقين بصريا. بناء على ما تقدم ذكره توجز الباحثة أهم مبررات مشكلة الدراسة فى الآتى: 
1- ارتفاع قلق المستقبل عند المعاقين بصريا له آثار سلبية فى مجالات الحياة الرئيسة النفسية والاجتماعية ويترتب عليه العديد من المشكلات الامر الأى يستدعى دراستها لتوفير

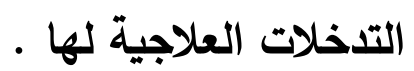

r- يعانى المراهقون المعاقون بصريا من إرتفاع واضح فى قلق المستقبل بما يستدعى توفير التخخلات العلاجية التى تتفق مع سماتهم الخاصة من أجل تحسينها . ץ- لا توجد دراسات عربية سعت للتصدى لمشكلة ارتفاع قلق المستقبل لاى المراهقين

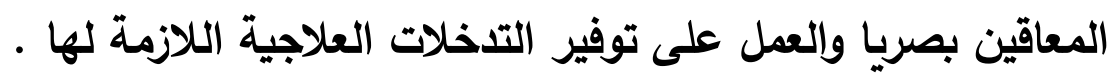
ع - إرتباط ارتفاع قلق المستقبل بانخفاض التوافق النفسى لاى المعاقين بصريا ـ مما حث الباحثة على ضرورة مساعدة المراهقين المعاقين بصريا لتجاوز معوقاتهم واستثمار ما لديهم من إمكانات تعينهم على التغلب على مشكلاتهم ـ وبذلك يمكن للباحثة صياغة

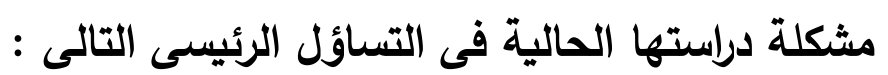
ما مدى فعالية البرنامج الإرشادى القائم على التفكير الإيجابى لتخفيف قلق المستقبل لاى

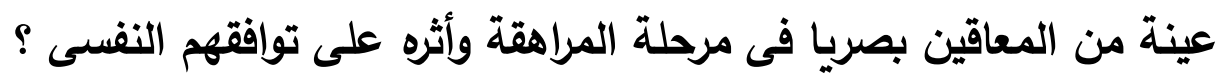
ومن خلال هذا التساؤل تنبثق التساؤلات الفرعية الأتية: 1- هل ينخفض قلق المستقبل لاى أفراد المجموعة التجرببية مقارنة بالمجموعة الضابطة بعد تطبيق البرنامج الإرشادى عليهم ؟ r- هل يزداد التوافق النفسى لاى أفراد المجموعة التجريبية مقارنة بأفراد المجموعة الضابطة بعد تطبيق البرنامج الإرشادى عليهم ؟ ئزدي r- هل يوجد إستمرارية لتاثير البرنامج الإرشادى على أفراد المجموعة التجريبية لكل من قلق المستقبل والتوافق النفسى بعد مرور شهرين من التطبيق ؟ ء - هل يوجد إختلاف فى قلق المستقبل والتوافق النفسى لاى أفراد المجموعة الضابطة فى حال عدم تطبيق البرنامج عليهم ؟ 


\section{أهداف الاراسةة:}

تسعى الاراسة الحالية إلى إعداد برنامج إرشادى قائم على التفكير الإيجابى للحد من قلق المستقبل لاى المعاقين بصريا.

\section{أهمية الاراسةة:}

تكمن أهمية الدراسة فى أهمية الموضوع الذى تتصدى لدراسته، حيث أن هذه الدراسة تنظوي على كثير من الأهمية سواء من الناحية النظرية أو الناحية التطبيقية :

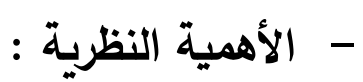
إن الكثير من الدراسات والبحوث التى أجريت فى دراسة مرحلة المراهقة وأزماتها بالرغم من

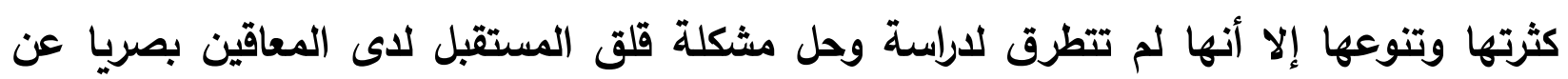

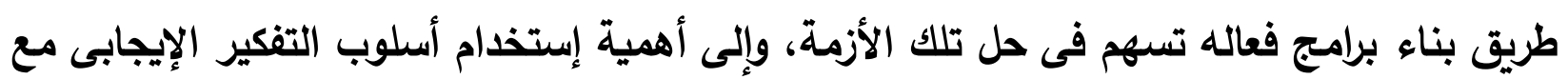

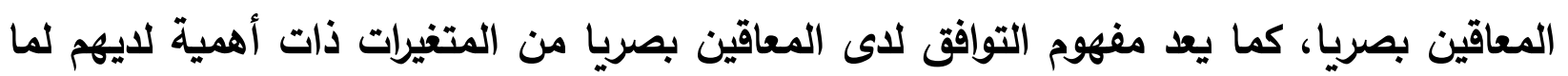

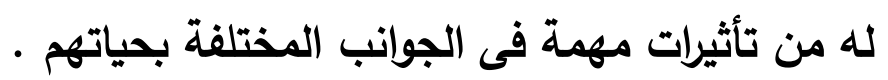
- الأهمية التطبيقية : يمكن أن توفر نتائج الدراسة الحالية البيانات والمعلومات التى تساعد فى التخطيط السليم

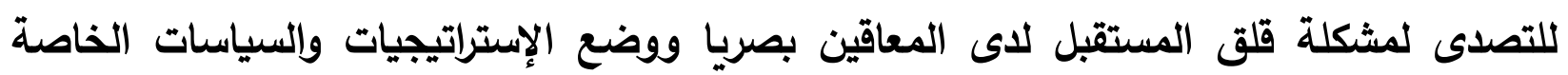

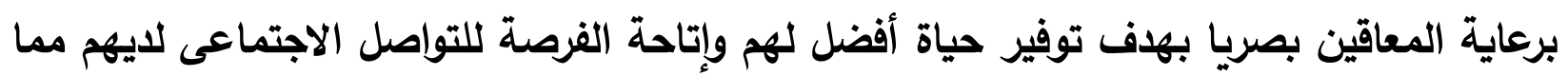
يزيد من توافقهم النفسى وإندماجهم فى المجتمع ومشاركتهم فى الحياة الإجتماعية بكافة جوانبها.

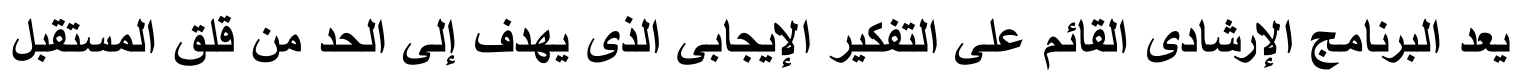

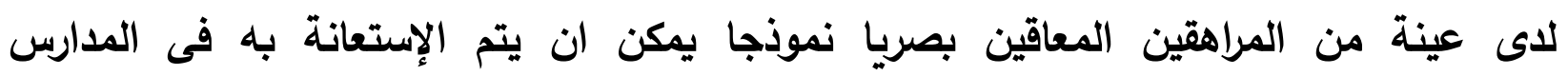

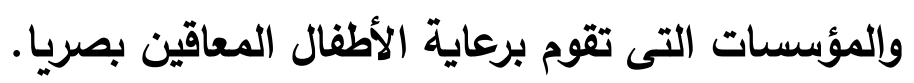

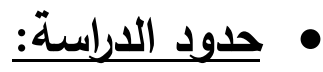

تتحدد الاراسة الحالية بحدودها البشريةٌة ، والمكانية ، والزمانية على النحو التالى: ا ـ الحدود البشرية : البة

تتحدد بعينة الدراسة المكونة من (• 1) طالبات من المراهقين الإناث المعاقين بصريا التى

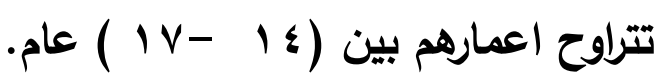


تتحدد بمكان إجرائها بمعه النور للمكفوفين - بثبين الكوم - بمحافظة المنوفية.

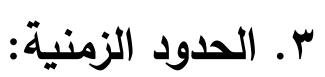

تتحدد إجراءات الدراسة على العينة السابق ذكرها فى الفصل الدراسى الثانى من العام

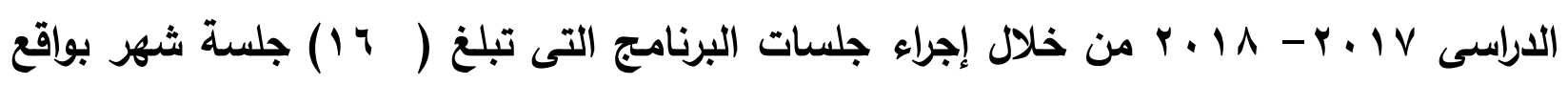

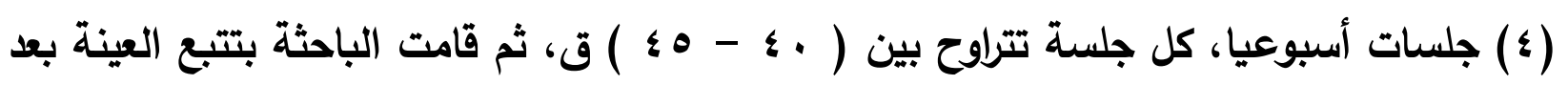
مرور شهر من إنقضاء البرنامج.

\section{مكونات الإطار النظري}

\section{أولا : قلق المستقبل :}

لقد أبدى الكثير من العلمـاء حماس شديد وإهتمام كبير بدراسـة الظروف والعوامل النفسية للفرد

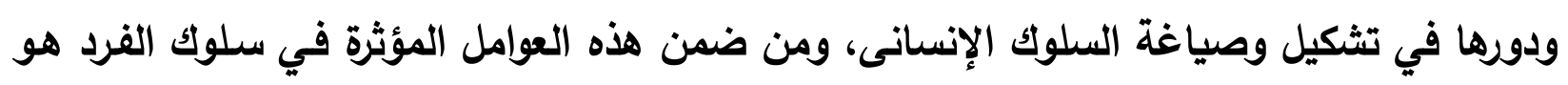
قلق قلق المستقبل.

وتقوم الباحثة بعرض الإطار النظرى لقلق المستقبل بعرض تعريف قلق المستقبل، ثم تنتقل

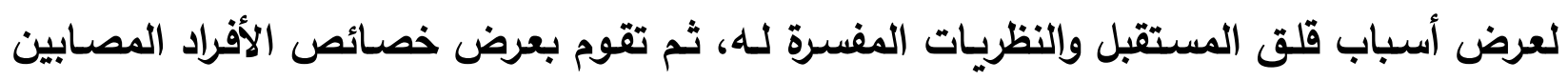
بقلق المستقبل.

\section{• تعريف قلق المستقبل :}

تناول العديد من الباحثين تعريف قلق المستقبل ومحاولة تحديد مفهوم له . حيث عرفته (سلوي عبد الباقي، ب99 9 1 : 1 1 ) بأنه "مزيج من الرعب والأمل بالنسبه إلي المستقبل، والاكتئاب والافكار الوسواسيه وقلق الموته الموته وإليأس بصوره غير معقوله ".

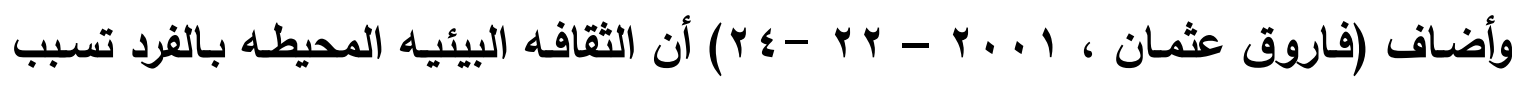
قدر كبير من التوتر والقلق اذا احتوت علي التعقيدات والاحباط أو المنتاقضات التي يثعر معها

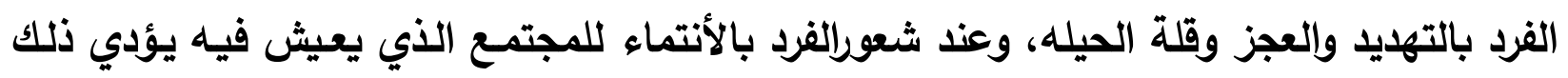

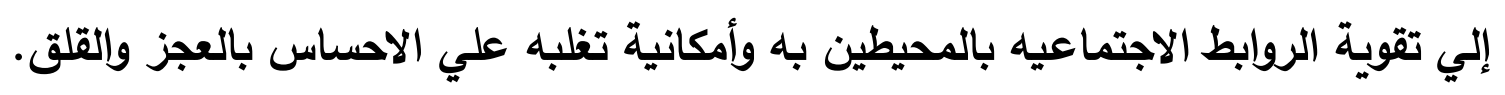




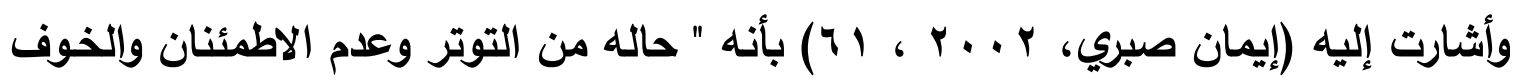

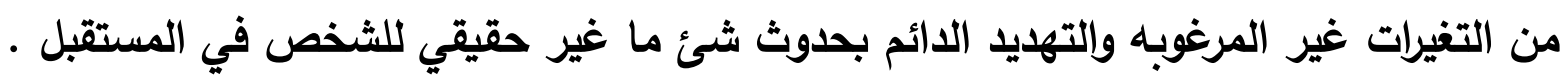

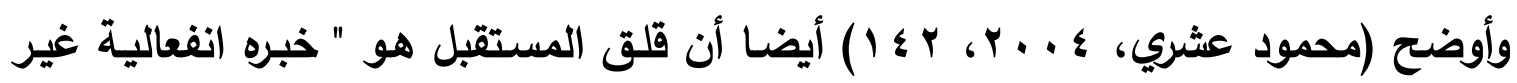

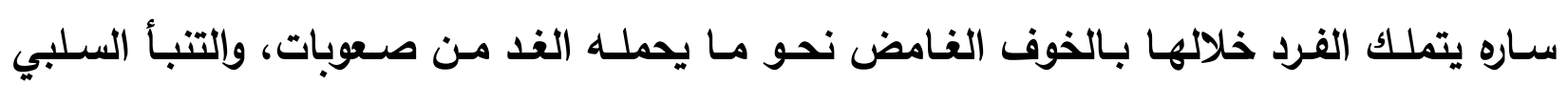

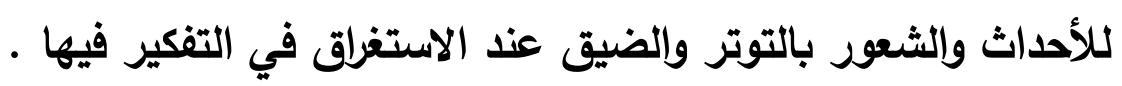

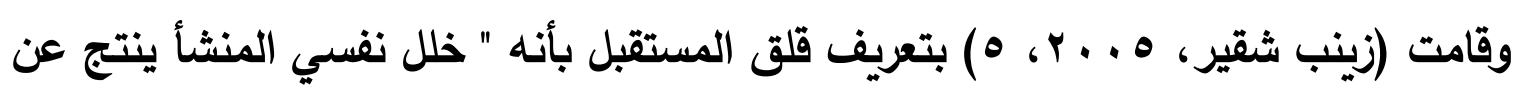

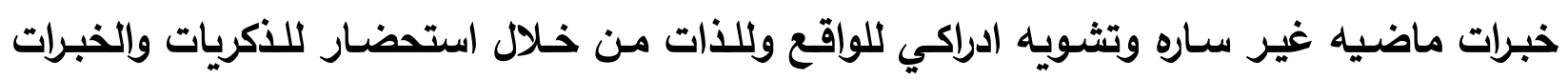

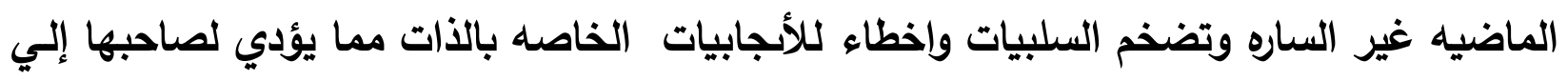

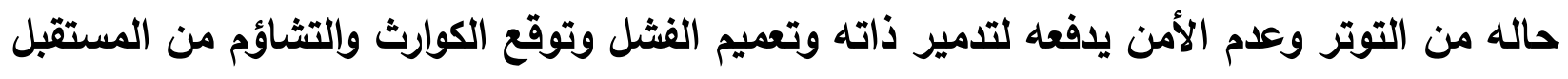
وقلق التفكير فيه والخوف من المدخلات الاجتماعيه والاقتصاديه المستقبليه المتوقعه والافكار الوسواسيه وقلق الموت واليأس ".

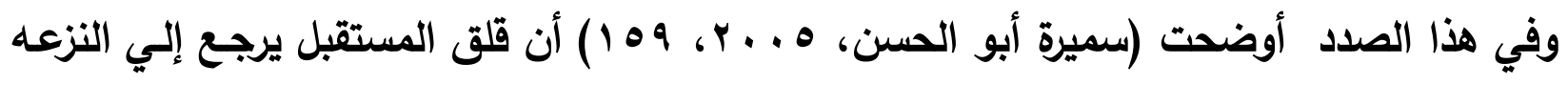

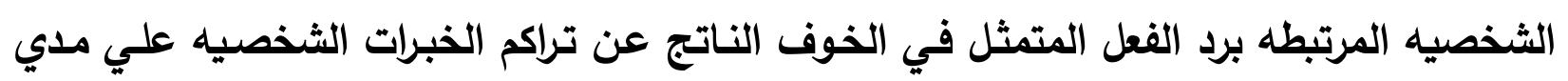

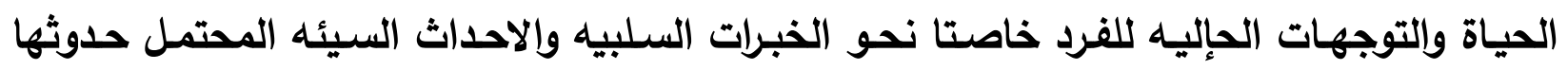

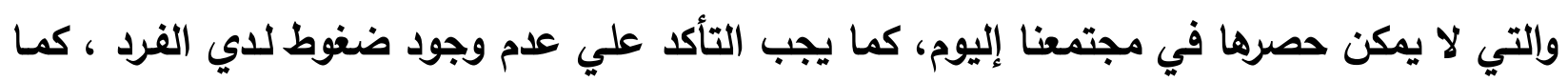

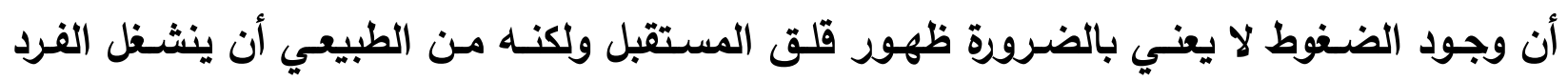

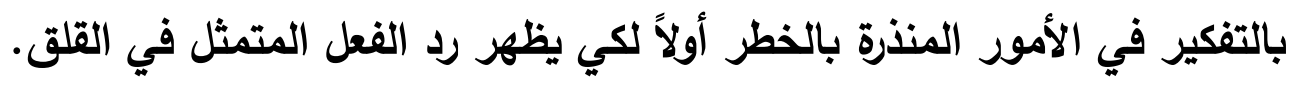

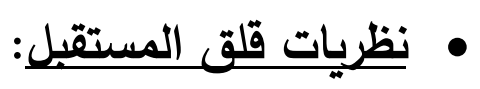
1- نظرية التحليل النفسي r- ب النظرية الوجودية

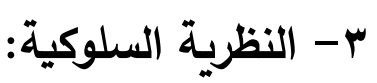

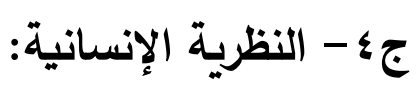
ه- النظرية المعرفية : •خصائص الأفراد المصابين بقلق المستقبل : لخص (Moline,1990,501-512) خصائص الأفراد المصابين بقلق المستقبل فيما يلي: 
1 - التشاؤم والإنظواء والثثك والتردد والإنفعال لأقل الأسباب.

r - الميل إلي التعقيد والاضطراب وعدم الاستقرار.

r- السلبية وفقدان الثقة في النفس.

ع - - صلابة الرأى والتعنت.

ه- الخوف من التغيرات الاجتماعيه والتوقعات السلبية لكل ما يحمله المستقبل.

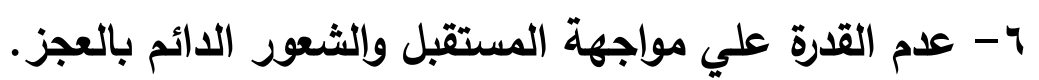

- الكذب والتصنع والإنسحاب والهروب اجتماعيا وثقافيا وعاطفيا.

ثانيا : التفكير الإيجابى:

وتقوم الباحثة بعرض الإطار النظرى للتفكير الإيجابى بتقسيمه إلى ستة محاور رئيسية،

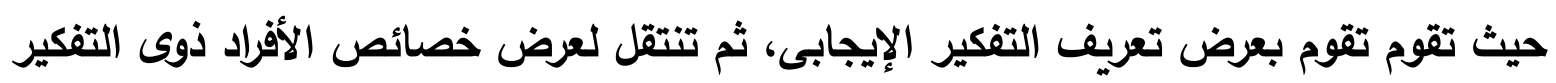

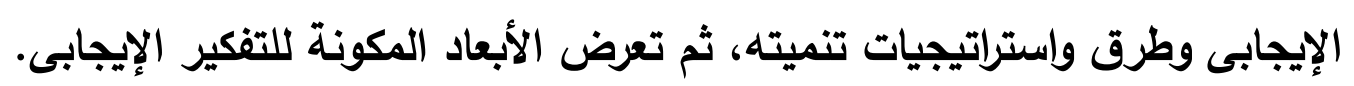
ينقسم الإطار النظري للتفكير الإيجابى إلي سته محاور رئيسية : • تعريف التفكير الإيجابى

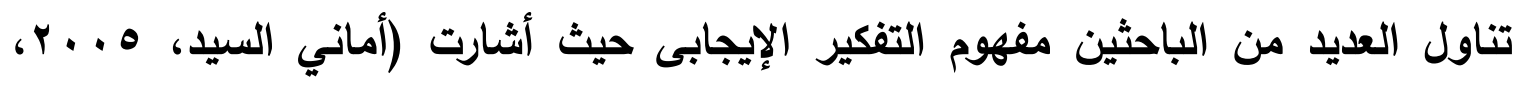

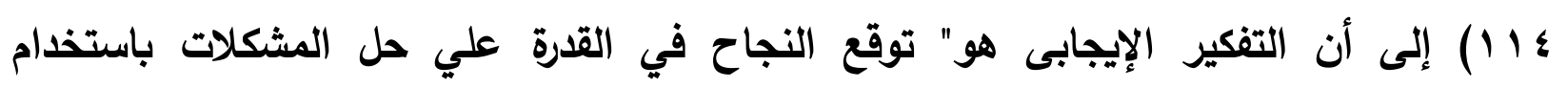

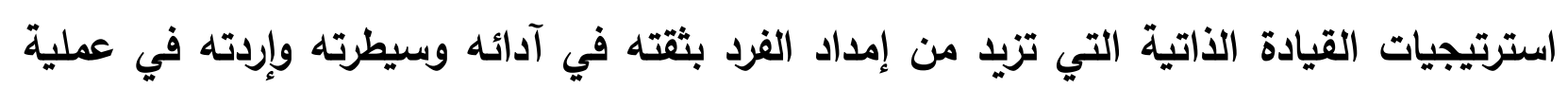

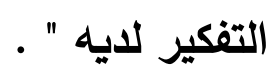

وأضاف (زياد بركات، 7 . . ץ : ؛ ) أن التفكير الإيجابى نثأ من عدة مفاهيم مختلفة منها

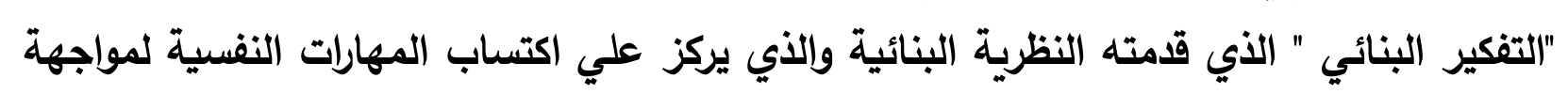
مشاكل الحياة وأيضا " التفكير الفرصة " الذي قدمه سوليفان الذي يركز علي زئي زيادة إنتباه الفرد وتفكيره في أبعاد النجاح في مشكلة الجوانب التي تؤدي إلي تحديد المشكلة وحلولها وليس التركيز

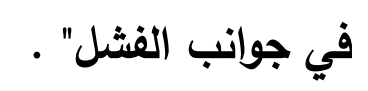
• خصائص الأفراد ذوي التفكير الإيجابي :

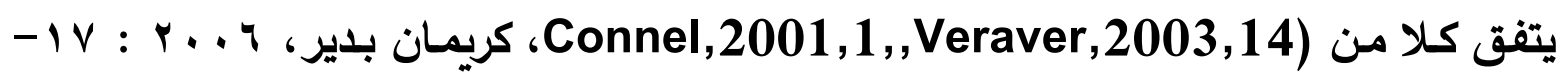

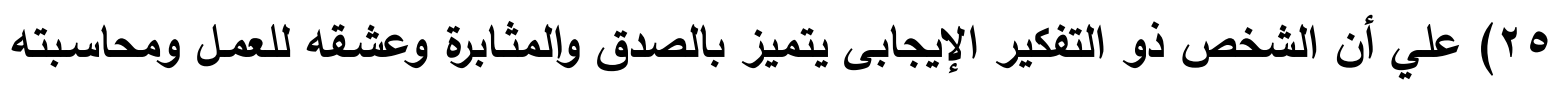
لنفسه باستمرار، كما يتسم أيضا بتواصل التفكير والعمل بروح الفريق ويبدوعليه في مظهره 
البسـاطة، ويكـون قادرا علـي الإعتراف بالخطأ وتحديد الجزئيـات وتحليلها وحل المشكلات،

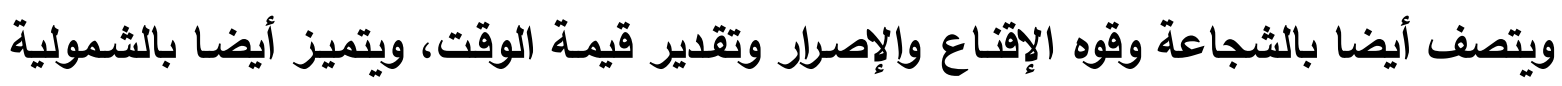
واللدقة في التخطيط والتركيز ويتصف بقبول الإختلاف والسلوك الجيد مـع الآخرين وإحترام نظامهم وأخلاقهم وقيمهم، والتوقع المتميز لردود أفعالهم .

استر|تيجيات تنمية التفكير الإيجابى :

1 - استراتيجية التفكير الإيجابى:

r

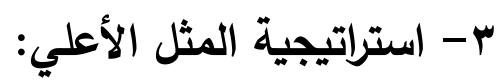

ع - استراتيجية الشخص الآخر:

0- استراتيجية إعادة التعريف :

צ- استراتيجية البدائل: - n

• أنواع التفكير الإيجابيى

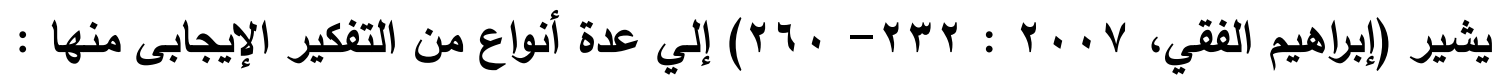
1- التفكير الإيجابى لتدعيم وجهات النظر :

وهذا النوع من التفكير يستخدمه البعض لتدعيم وجهات نظرهم الثخصية في شئ

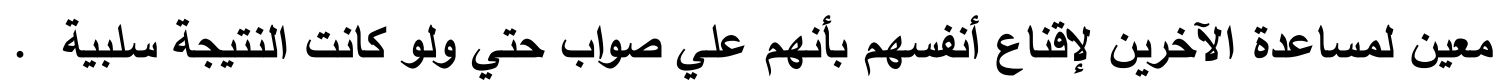
r. التفكير الإيجابى بسبب التآثر بالآخرين :

وهذا النوع من التفكير يحدث بسبب التآثر بثخص آخر سواء من الآقارب أو الآصدقاء أو بسبب

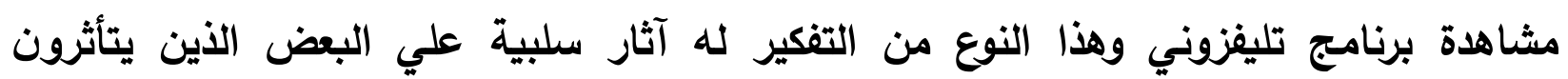

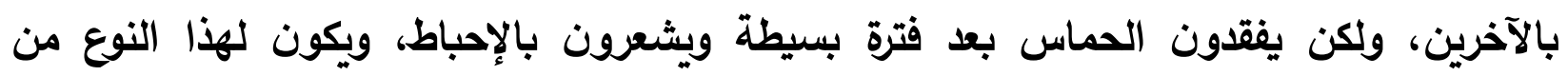
التفكير آثار إيجابية أيضا فيدفع الفرد إلي المبادأة وعدم إستغلال وقته فى السلبيات وإستغلالها فى ولى وليطي الفعل والتقييم والتعديل حتي يصل لأهدافه ويحققها. ب- التفكير الإيجابى بسبب التوقيت : 
ويستخدم هذا النوع من التفكير الإيجابى لتحسين سلوكياتنا وبناء عادات إيجابية جديدة، كما يقوم بعض الأفراد من سلوكيات في شهر رمضأن وفي الثهور الروحانيه. ع - التفكير الإيجابى في المعاناة:

وهذا النوع من التفكير إما أن يجعل أفراده يقتربون أكثر من الله سبحانه وتعالي عند مواجهتهم

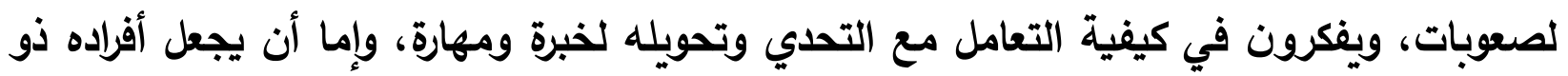

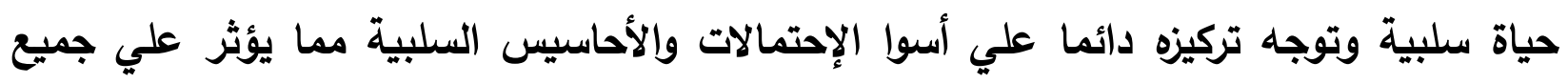

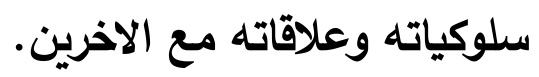
ه- التفكير الإيجابى المستمر في الزمن :

وهذا النوع من التفكير لا يتأثر بالزمان أو المكان أو بأى نوع من أنواع المؤثرات بل هو التهات

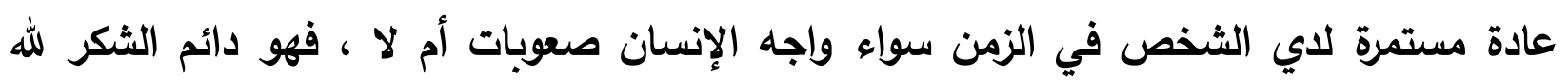

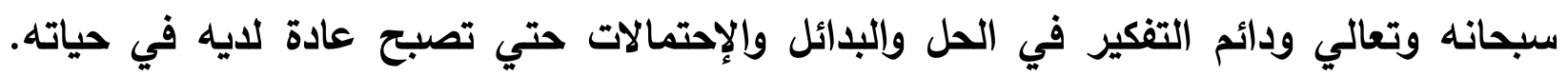

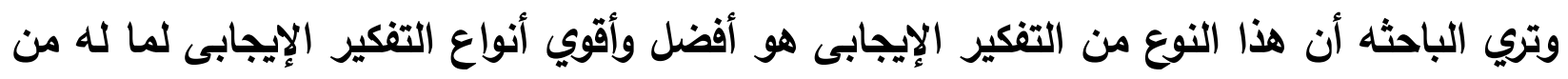
آثار إيجابية تجعل حياة الفرد سعيدة ومتزنة وهادئة باستمرار.

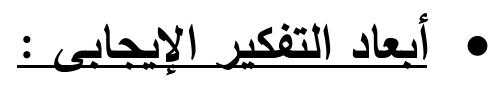
1- 20 - التفاؤل والتوقعات الإيجابية

r- الضبط الإنفعالى والتحكم فى العمليات العقلية: ب- التقبل الإيجابى للإختلاف عن الآخرين:

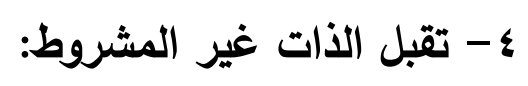
ثالثا : الإعاقة البصرية : وتقوم الباحثة بعرض الإطار النظرى لهذا الجزء بعرض تعريف الإعاقة البصرية،ثم عرض الإض تصنيفها، ثم الانتقال لعرض خصائص الأفراد المعاقين بصريا.

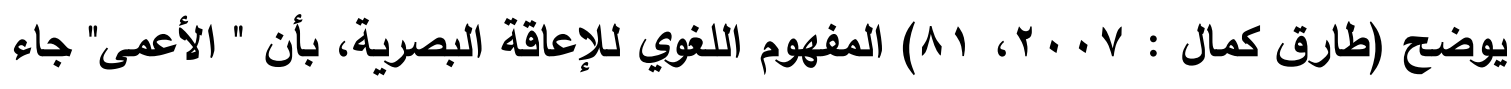
من مصطلح " عماء" وهو الضلالة، وهو الثخص الذي أصيب بعجز جزئي فى بصره . 


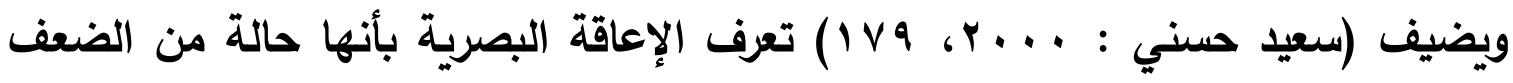
فى حاسة البصر تحد من قدرة الفرد على إستخدام بصره (العين) بفاعلية وإقتدار، مما يؤثر سلبا

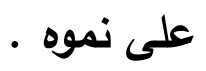

\section{• ت تصنيف الإعاقة البصرية :}

وتضيف (نظيمه سرحان، ؟ . . ץ: 01) تصنيف للإعاقة البصرية فمن حيث درجه الإصابة

بكف البصر فتصنفها إلى :

$$
\text { 1- كف بصر كلي : }
$$

ويغني الفقدان الكامل للقدرة على الإبصار .

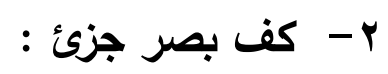

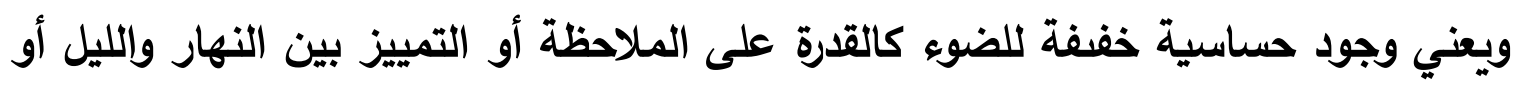

بين مصادر الضوء المختلفه وهذه القدره رغم قيمتها الحيويه فى حياة الكفف جزئئيا إلا أنها لا لا تساعدة على الرؤية الحقيقية ويقتبر فى حكم المكفوفن عمليا .

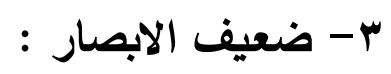

وهي أخف درجات الإصابة ويستطيع صاحبه تحصيل المهارات والقيام بأعمال مستخدما بصرة مع لستخدام الحواس الآخري .

رايعا : التوافق النفسى :

وتقوم الباحثة في هذا الجزء بعرض الإطار النظرى للتوافق النفسى ، ثم تنتقل لعرض الأبعاد

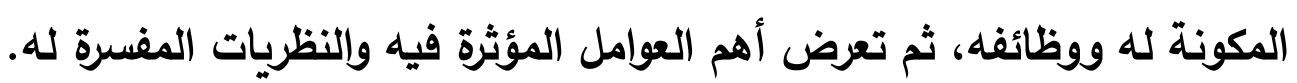
• ت تعريف التوافق النفسى :

لقد إجتها العلماء والباحثين فى تعريف التوافق النفسى، وقد قاموا بتعريفه بمعاني كثيرة،

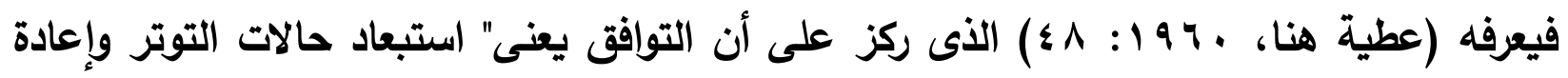
الفرد إلى مستوى توازنه الانى يعيش فيه" . 
إختلف الأراء حول تحديد أبعاد التوافق النفسى نتيجة لإختلاف نظرة العلماء والباحثين فقد

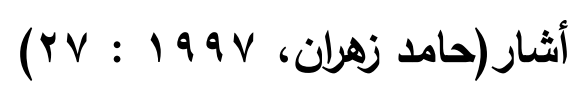

إلى ثلاث أبعاد للتوافق وهى التوافق الثخصى والتوافق الإجتماعى، والتوافق المهنى .

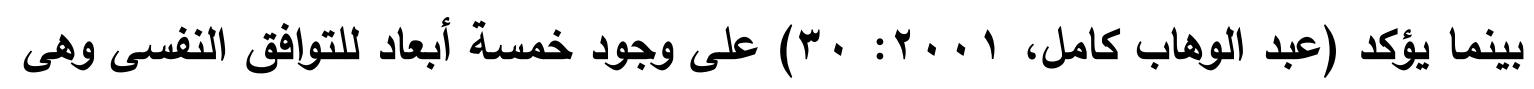

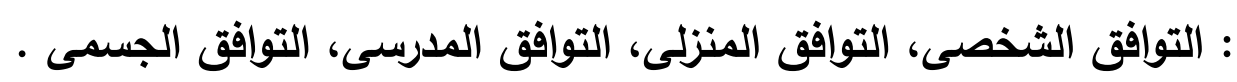
• وظائف التوافق النفسى :

فالتوافق يتضمن المرونة فى مواجهة الظروف البيئية، وتغيير وتعديل سلوك الفرد لإشباع رغباته طبقا لأى تغير يحدث فى البيئة المحيطة بالفرد، وهناك عدة عوامل تؤثر فى عملية التوافق منها : 1- إثباع الحاجات الأولية r - - إثباع الحاجات الثانوية r- - التقبل والرضا عن الذات

ـ - المسايرة والتكيف مع المجتمع وقيمته ومعاييرة : - تحقيق الصحة النفسية : • العوامل المؤثرة فى التوافق :

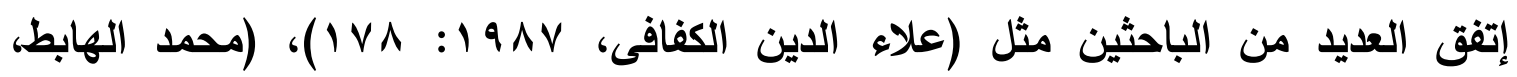

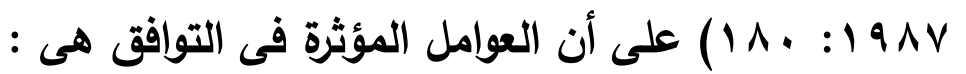
1- التنشئة الاجتماعية r - خبرات الطفولة : r - - المكونات الجسمية צ - وسائل الإعلام والإتصال: ه- الظروف الإقتصادية: ץ- - توفر المهارات التكيفية 
النظريات المفسرة للتوافق النفسى

النظرية البيولوجية الطبية

- نظرية التحليل النفسى -

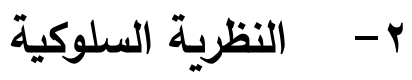

النظرية الإنسانية

وقد قامت الباحثة بتقسيم الدراسات السابقة إلى عدة محاور وهي ، على النحو الآتي : أولاًً : دراسات تناولت قلق المستقبل وعلاقته ببعض المتفيرات النفسية ومدى انتثاره : •دراسة ( محمد القحطاني ، 19 • • ) ) :

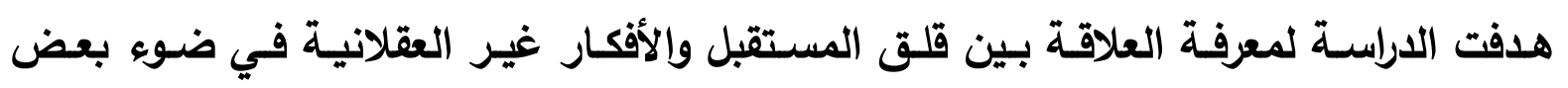

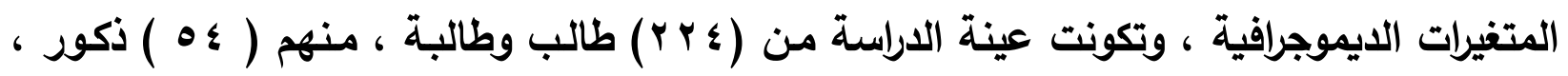

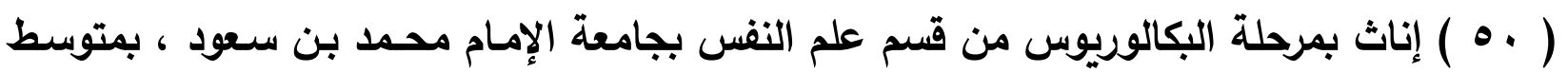

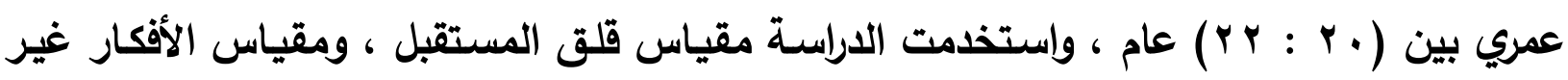

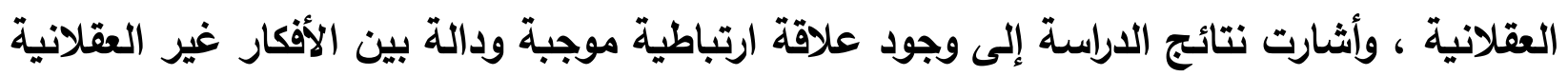
وقلق المستقبل في الأبعاد " قلق المشكلات الحياتية - قلق الصحة وقلق الموت - القلق الذهني - قلق التفكير في المستقبل " ولا توجد علاقة دالة بينهم في البعدين " اليأس من المستقبل الخوف والقلق من الفثل في المستقبل" . • دراسة ( سميرة ميسون ، ربحه بوعزة ، 1 • ب r ) )

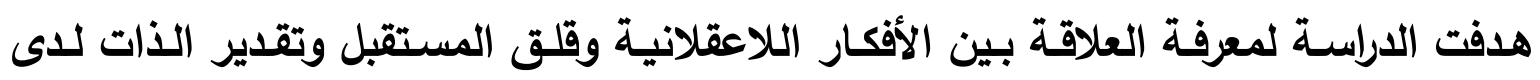

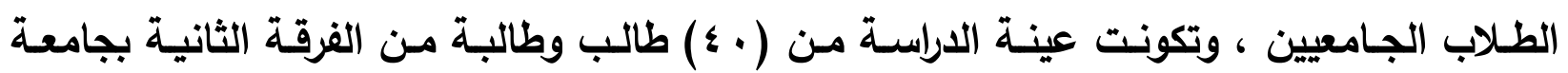

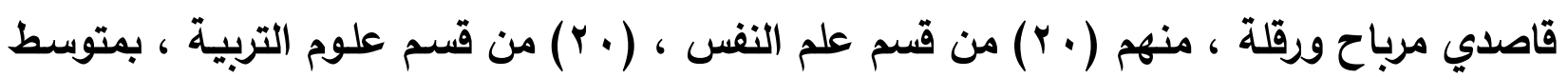

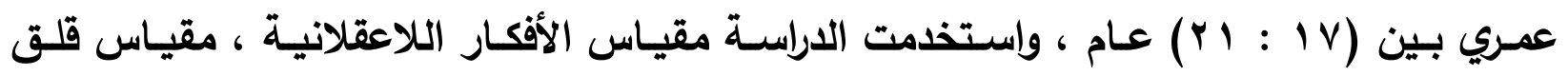

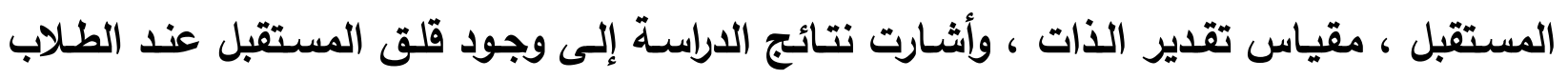

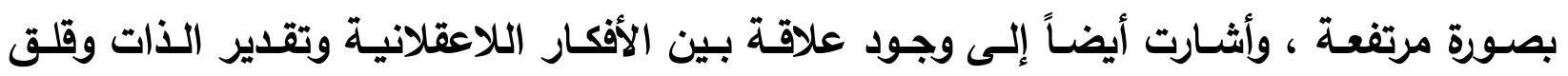

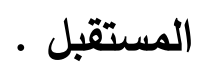




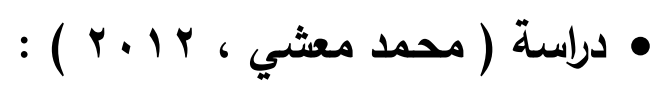

هدفت الدراسة لمعرفة مستوى قلق المستقبل لاى الطالب المعلم ، ومدى اختلاف درجة قلق

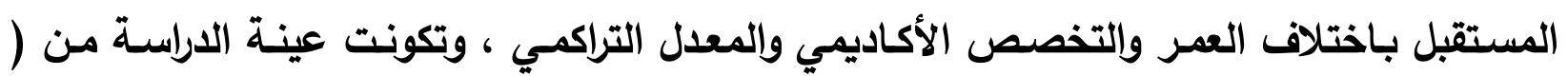

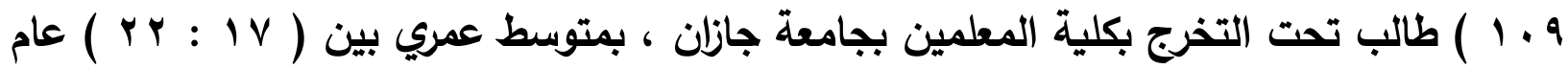
، واستخدمت الدراسة مقياس قلق المستقبل ، وأشثارت نتائج الدراسة إلى وجود مستوى مرتفع من ، قلق المستقبل من الطلاب المعلمين ، وأشـارت أيضاً لعدم وجود فروق دالتة في درجة القلق تعود لاختلاف العمر الزمني والتخصص الأكاديمي والمعدل التراكمي لاي الطلاب المعلمين . ثانياً : دراسات تناولت البرامج العلاجية لقلق المستقبل :

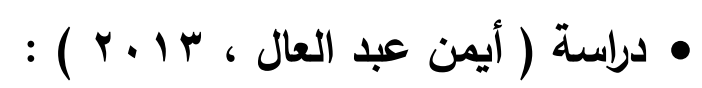

هدفت الدراسـة لمعرفة أثر وفعالية العلاج المعرفي السلوكي في خفض قلق المستقبل للى

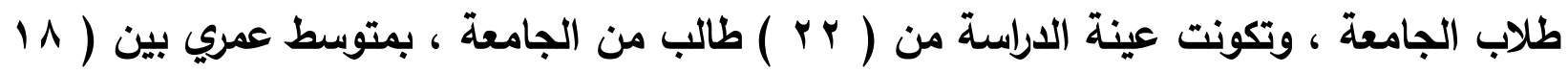

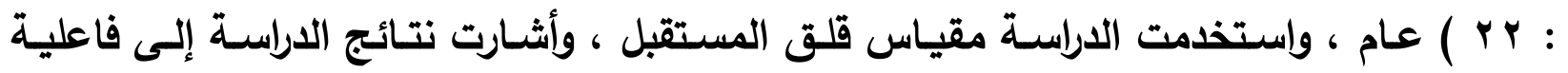
ونجاح العلاج المعرفي السلوكي في تقليل قلق المستقبل .

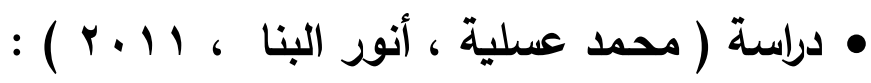

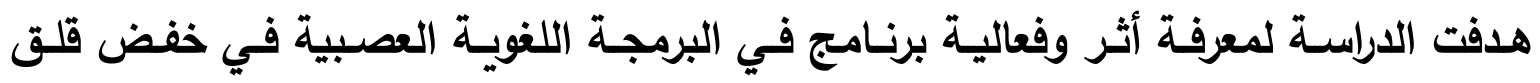

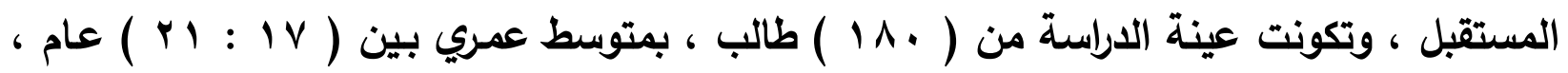
واستخدمت الدراسـة مقياس قلق المستقبل ، برنـامج قائم على البرمجة اللغويـة العصبية وأثـارت

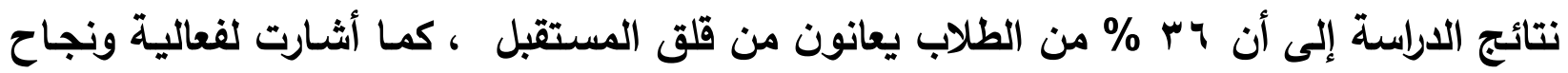
البرنامج المستخدم في العلاج •

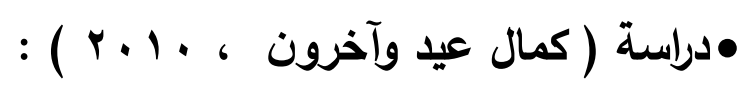

هدفت الدراسـة إلى التعرف فاعلية أسلوب لعب الدور كأحد فنيات العلاج بالسيكودراما في

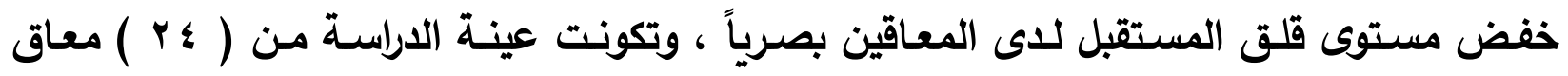

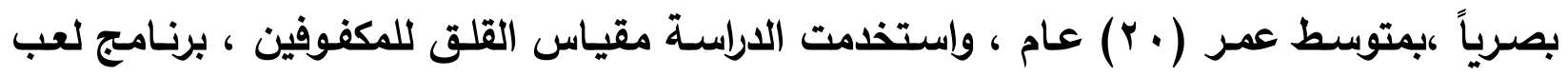

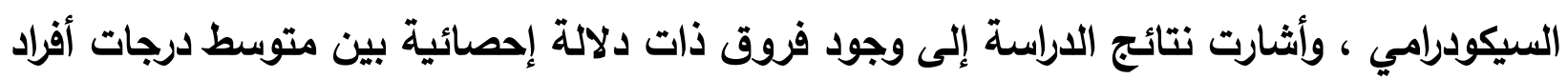

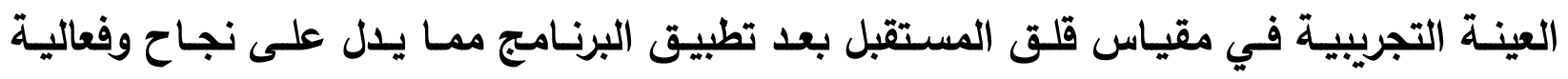
· البرنامج 
ثالثاً : دراسات تناولت التفكير الإيجابي وعلاقته بيعض المتفيرات النفسية : : (Stoeber , Corr , 2017) دراسة

هدفت الدراسة إلى معرفة العلاقة بين نظرية الحساسية للتعزيز والكمال الذاتى متعددة الأبعاد

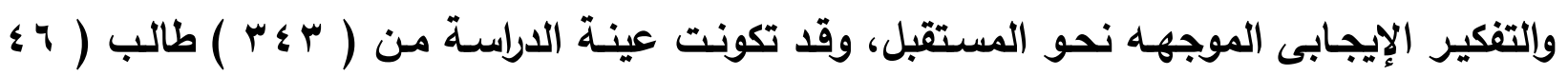

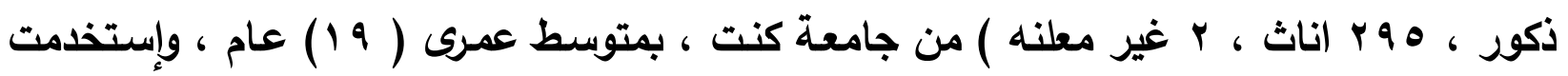

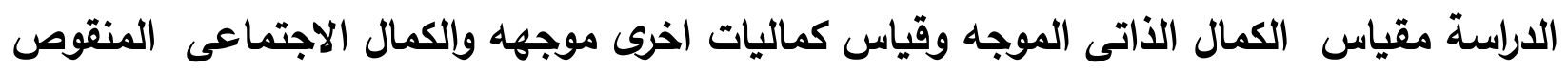

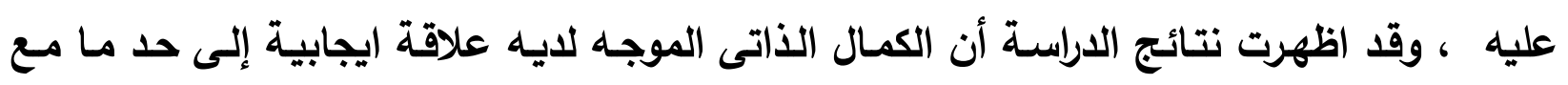

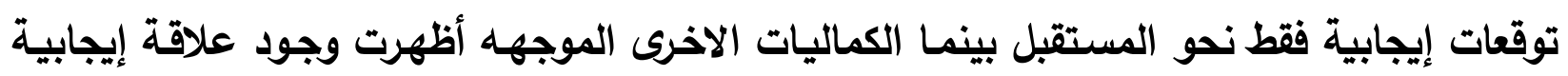

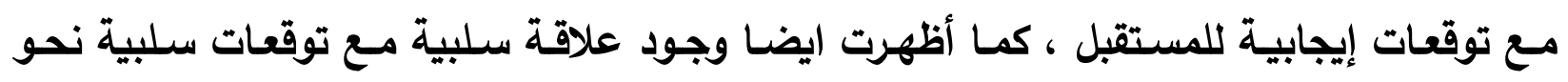

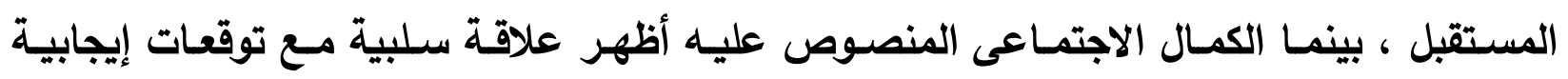
للمستقبل وكذلك وجود علاقات ايجابية مع توقعات سلبية للمستقبل . : (Trick, et al . , 2016) دراسة (1)

هدفت الاراسة إلى دراسة العلاقة بين التفكيرالإيجابى والسلبى المتكرر (المثابر) والأكتئاب ،

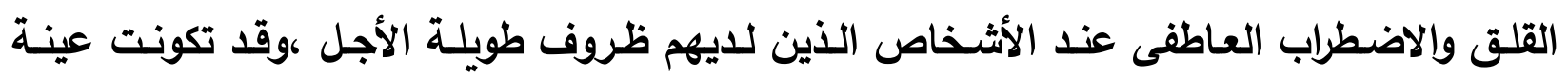

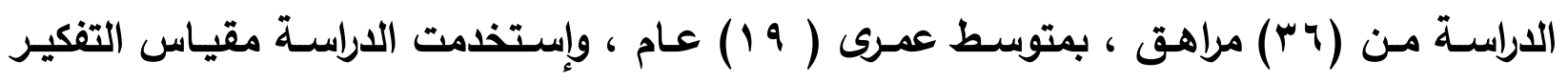

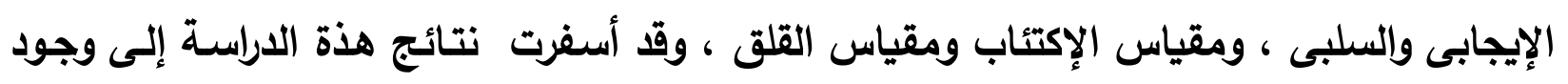

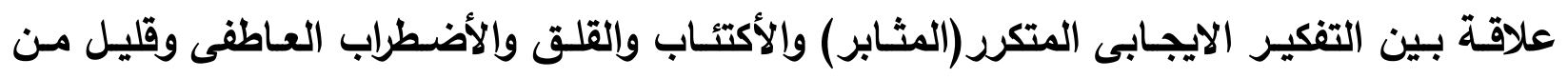
الدراسات قيمت تأثير التفكير السلبى المتكرر ( المثابر) على النواتج الجسدية (الطبية) . : (Gaber، 2016 ) دراسة

هدفت الدراسة لاراسة العلاقة بين التفكيرالإيجابى ومستوى الطموح وقلق المستقبل وتأثيرها

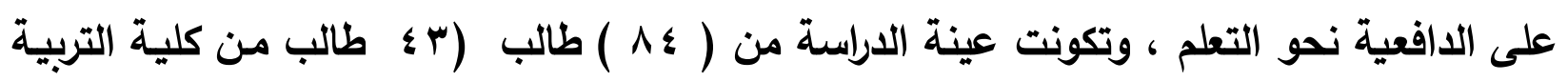
و 1؛ من كلية الهندسة فى نجران)، وقد استخدمت الدراسة مقاييس متعددة وهى مقياس الدافعية نحو التعلم ، ومقياس مستوى الطموح ومقياس قلق المستقبل واختبار كاليفورنيا لمهارات التفكير

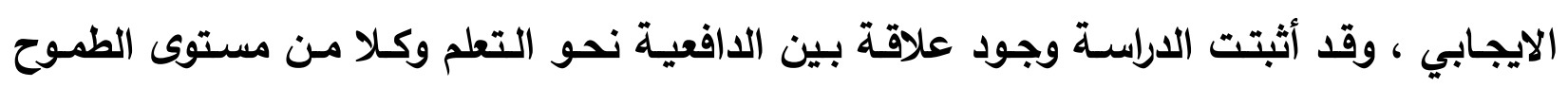

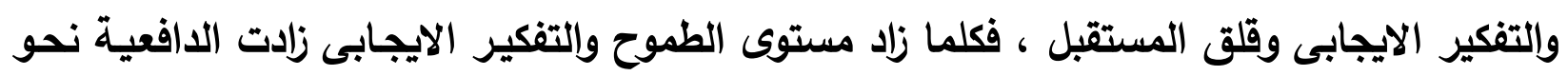

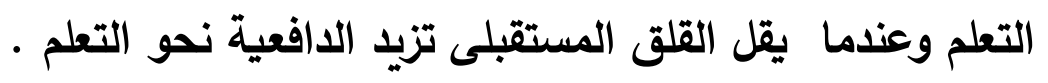


رابعاً : دراسات تناولت برامج تنمية التفكير الإيجابي وأثرها على بعض المتغيرات :

$$
\text { • دراسة ( مروى عبد الوهاب ، } 10 \text { • ب ) ) : }
$$

هدفت الدراسـة لمعرفة فعالية وأثر برنـامج تدريبي لتنمية مهارات التفكير الإيجابي لخفض

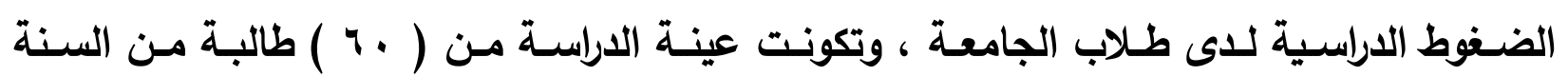

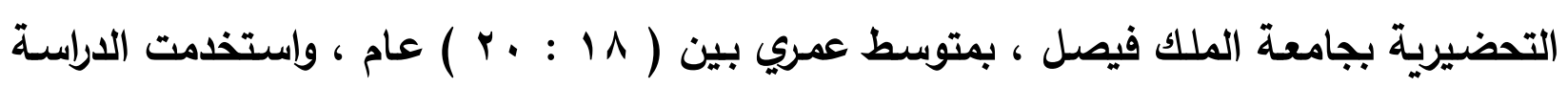

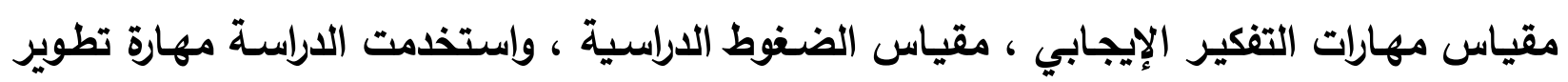

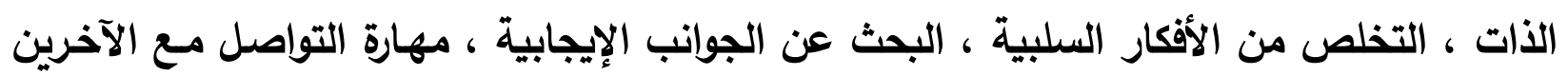

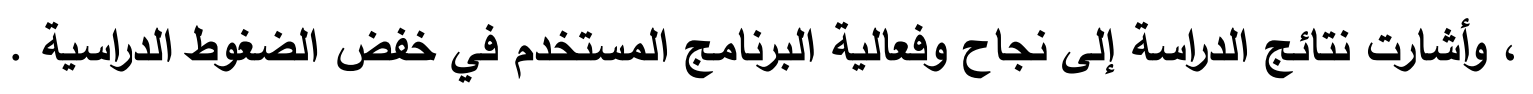

$$
\text { • دراسة ( صفاء فرغلي ، ؛ } 1 \text { • ب ) : }
$$

هدفت الاراسة معرفة أثر وفعالية برنامج تدريبي لخدمة الجماعة في تنمية التفكير الإيجابي

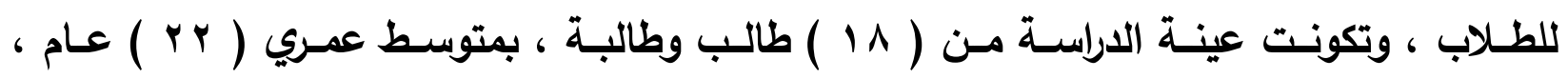

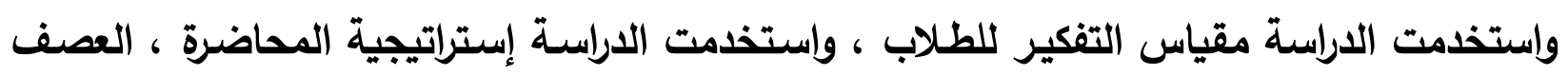

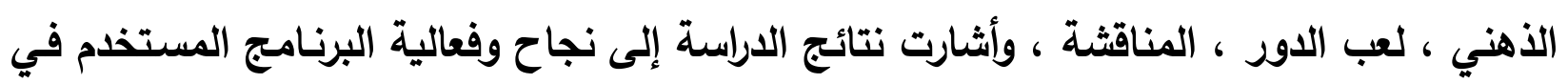

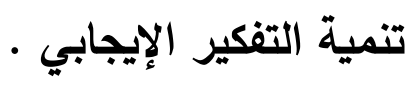

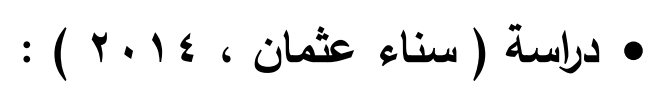

هدفت الدراسة لمعرفة أثر وفعالية برنامج إرشادي لتنمية التفكير الإيجابي لتحسين مستوى

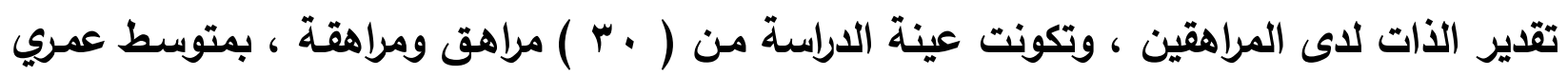

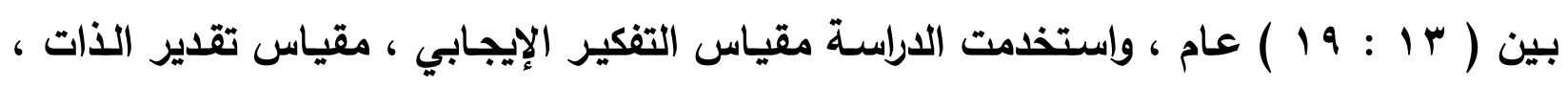

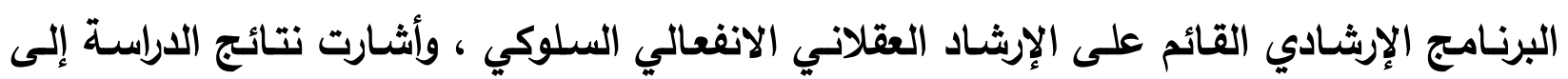

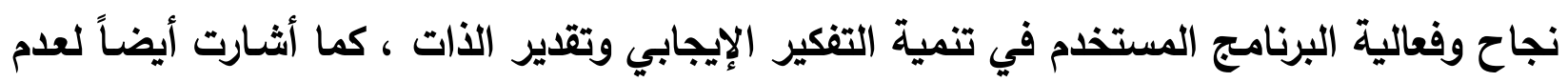
وجود فروق دالة إحصائياً بين متوسط درجات الذكور والإناث في التفكير الإيجابي . خامساً : دراسات تناولت التفكير الإيجابي في تنمية أو خفض بعض المتغيرات :

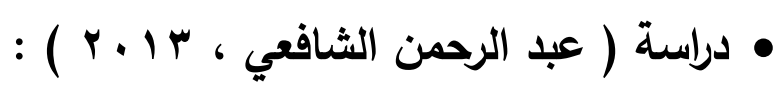
هدفت الاراسة إلى معرفة أثر برنامج للتفكير الإيجابي والتدعيم الذاتي على الآداء الأكاديمي

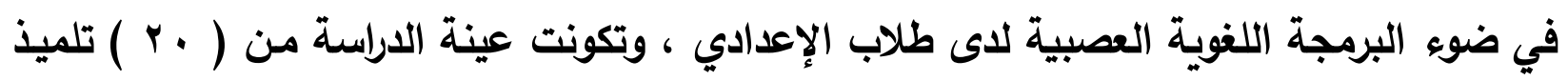


في الصف الثالث الإعدادي ، بمتوسط عمري بين (10 : 17 ) عام ، واستخدمت الاراسة اختبار

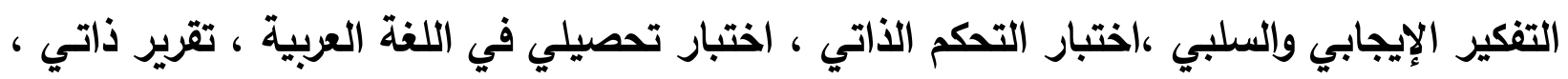

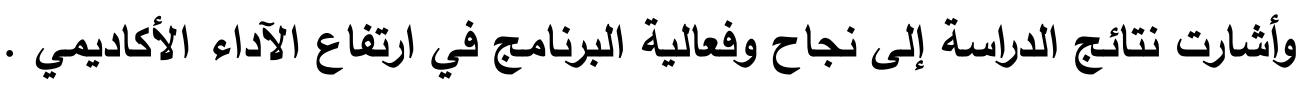

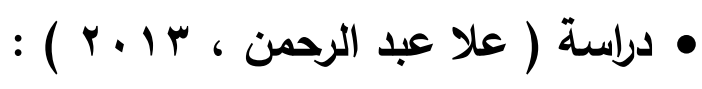

هدفت الدراسـة إلى معرفة أثر برنـامج للتفكير الإيجابي لتحسين جودة الحياة لاى معلمات

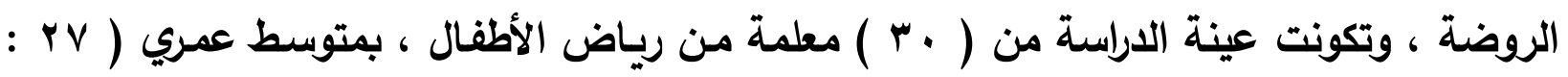

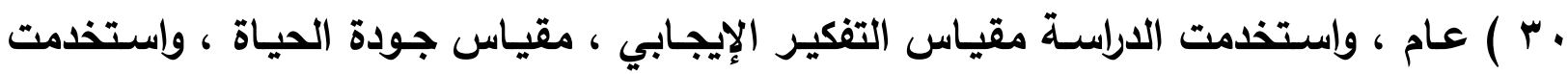
الدراسة إستراتيجية " التحدث الذاتي - حل المشكلات- المحاضرة - العصف الذهني - المناقشـة الإنة

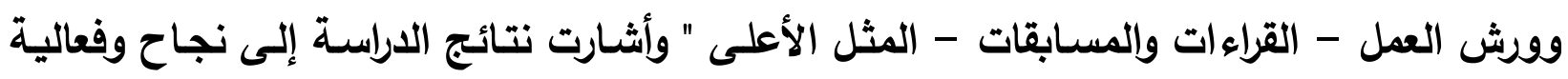
البرنامج في تحسين جودة الحياة . : • دراسة ( Fuxjager\& Lopez,2012) تهاف الدراسة لتوضيح دور التفكير الايجابى فى تعديل الادراك الذاتى لاى المراهقين،

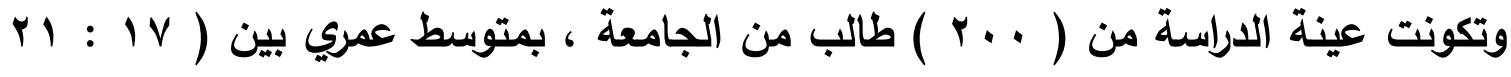

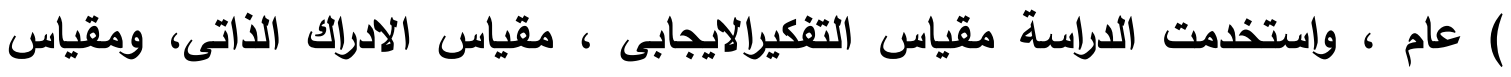
الخداع الذاتى، وقد أشارت نتائج الدراسة إلى وجود علاقة إيجابية دالة بين التفكير

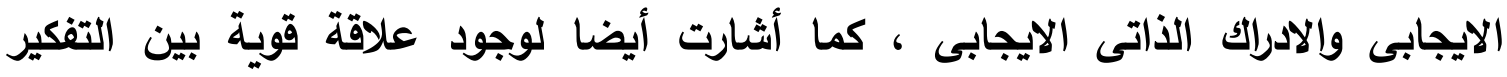

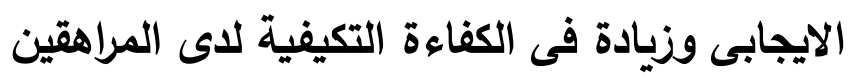

سادساً : دراسات تناولت التفكير الإيجابي وقلق المستقبل لاى المعاقين بصرياً :

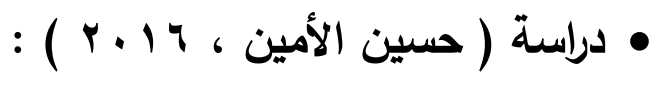

هدفت الاراسـة إلى التعرف على مهارات التواصل وعلاقتها بأسـاليب التفكير الإيجابي للاى

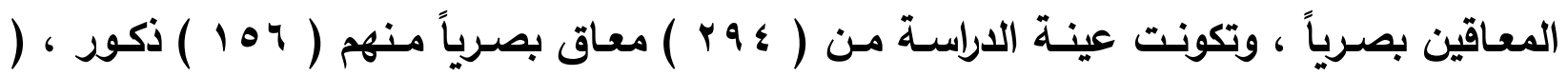

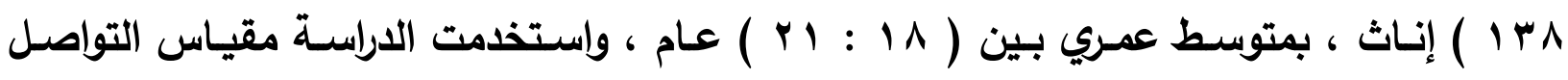
الاجتماعي ، مقياس أساليب التفكير، وأثارت نتائج الدراسة على ارتفاع دال إحصائياً في التواصل

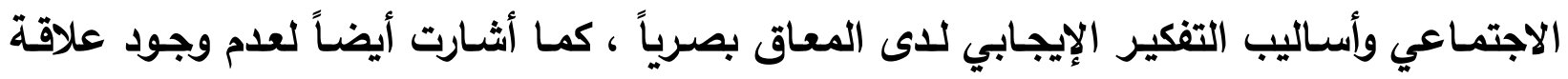

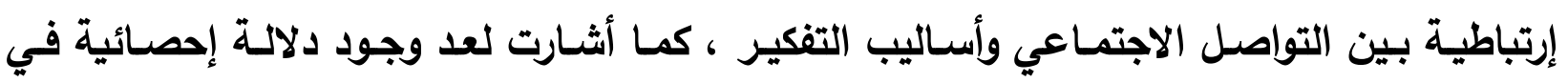


مهارات التواصل الاجتماعي لدى المعاق بصرياً تعزي لمتغير النوع لصالح الذكور ، وتوجد فروق

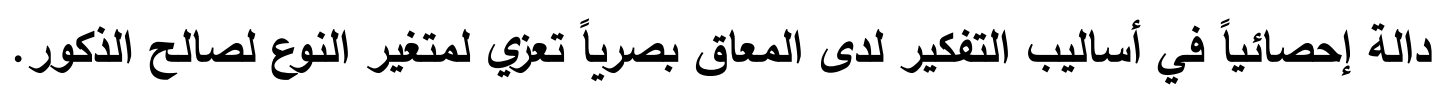

$$
\text { : Andrew , et al , } 2015 \text { ) (دراسة (1) }
$$

هدفت الدراسـة إلى الكثف عن علاقة التفكير الإيجابي والسلبي بقلق المستقبل ومحاولات

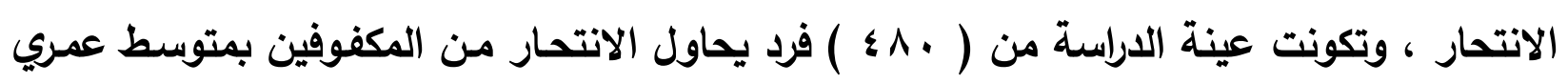

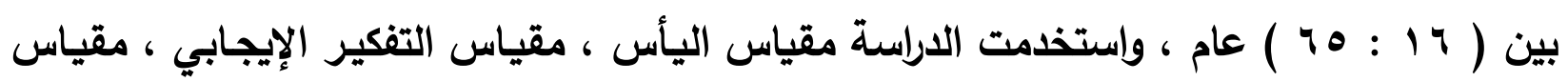

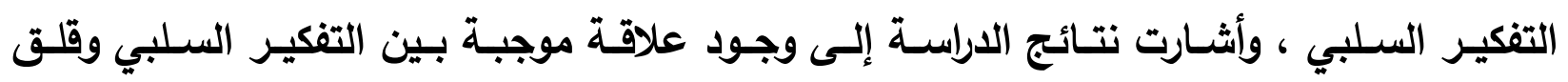

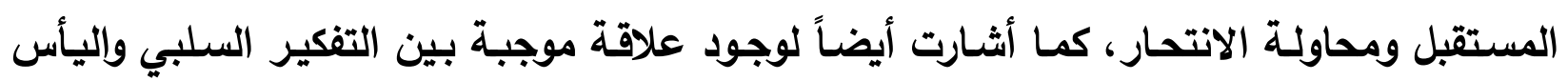

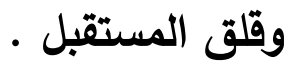

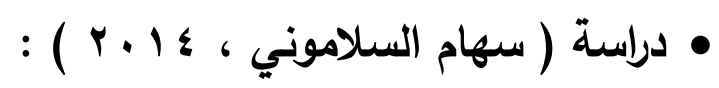

هدفت الدراسـة إلى معرفة أثر وفعالية برنامج إرشادي لتنمية التفكير الإيجابي للى أمهات

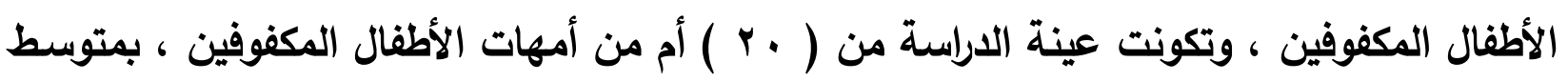

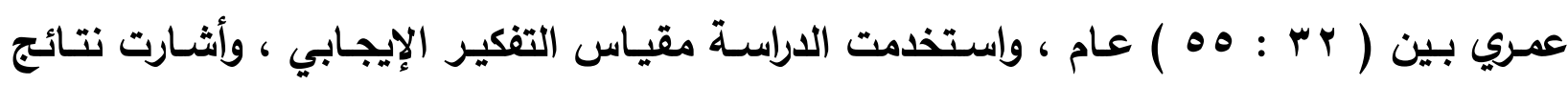

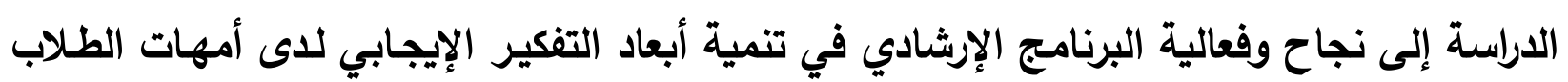

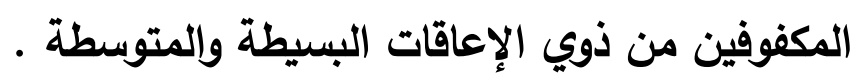

: (Hogendoorn, et al , 2012 ) دراسة

هدفت الاراسة إلى الكشف عن التفكير الإيجابي لاى الأطفال ذوي اضطراب قلق المستقبل ،

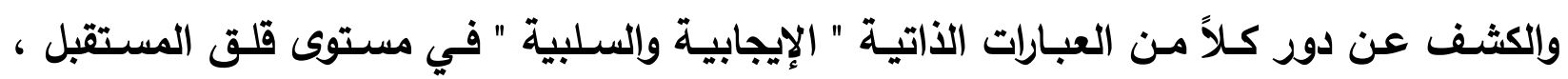

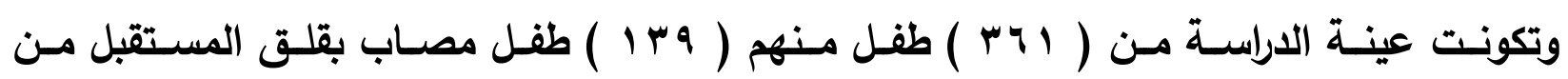

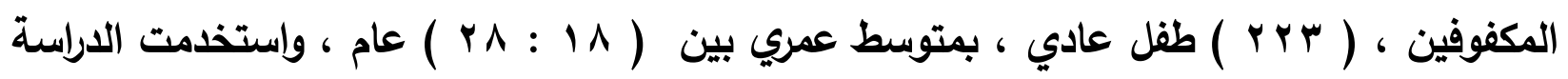
مقيـاس التفكيـر الإيجـابي ، مقيـاس قلـق المسـتقبل ، وأثــارت نتـائج الدراســة إلـى أن الأطفـال

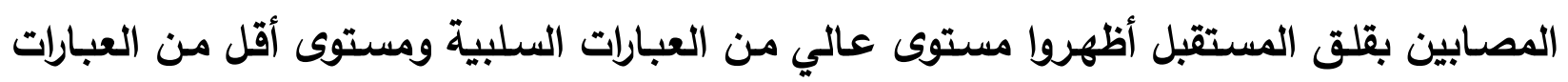

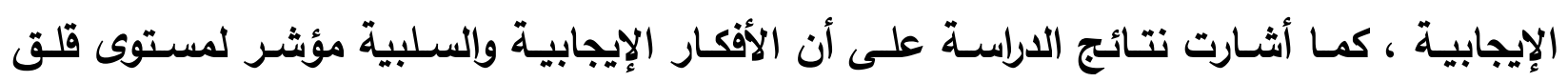

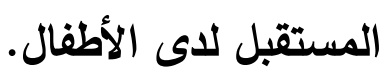


تسعى الباحثة من جراء إعداد الدراسة الحالية إلى التحقق من الفروض الأربعة الآتية . ا - وجود فرق ذا دلالة إحصائية (عند مستوي I +,.•) بين درجات عينة البحث من المعاقين بصريا في التطبيقين القبلي والبعدي لاختبار التوافق النفسي لصالح التطبيق البعدي ككل ولأبعاده الفرعية. r - وجود فرق ذا دلالة إحصائية (عند مستوي I +.,.) بين درجات عينة البحث من المعاقين بصريا في التطبيقين القبلي والبعدي لاختبار قلق المستقبل لصالح التطبيق البعدي ككل ولأبعاده الفرعية. r- لا يوجد فرق ذا دلالة إحصائية بين متوسط رتب درجات عينة البحث في اختبار التوافق النفسي في التطبيقين البعدي والتتبعي." ع - لا يوجد فرق ذا دلالة إحصائية (عند مستوي هـ ه.,.) بين درجات عينة البحث من المعاقين بصريا في التطبيقين التتبعي والبعدي لاختبار قلق المستقبل.

\section{الإجـــــــاءت}

\section{• أولا: منهج البحث :}

إقتضت طبيعة البحث الإعتمـاد على المنهج شبه التجريبي كمنهج مناسب للاراسـة شبه تجريبية تستهدف التعرف على فاعليه برنـامج إرشـادى قائم على التفكير الايجابى لتخفيف قلق المستقبل لاى عينة من المعاقين بصريا في مرحلة المراهقة ثانيا: التصميم التجريبي المستخدم :

إعتمدت الباحثة على التصميم التجريبي للمجموعة الواحدة "التجريبية "، وبثلاثة إختبارات قبلى، وبعدى، وتتبعى، وفى هذا النوع من التصميمات بحيث يجرى تطبيق أدوات القياس قبل تطبيق البرنامج (إختبار قبلى)، ثم يعرضون للمعالجة المطلوبة- المتغير المستقل - وهو البرنامج

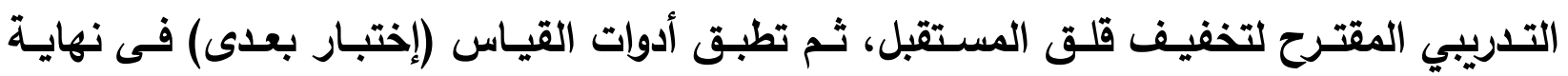

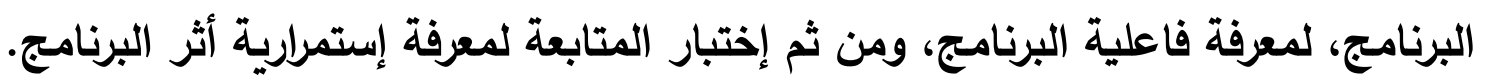


قامت الباحثة بإختيار عينة الاراسة من طلاب مرحلة المراهقة من المعاقين بصريا بمعهد النور للمكفوفين - التابع لإدارة شبين الكوم- مديرية التربية والتعليم محافظة المنوفية. وكان عدد العينة التجريبية فى بداية البرنامج (• † ) من المعاقين بصريا من الاناث ثم أخد

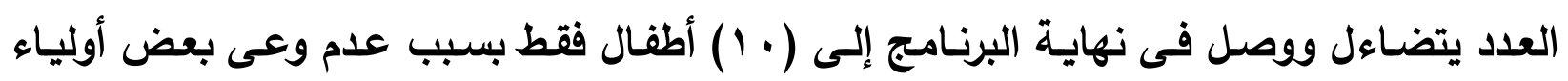
الأمسور بأهمية البرنـامج ، بالإضـافة إلى عدم حرص اولياء الأمور على حضور أبنائهم بصورة مستمرة للمدرسة بسبب ظروف مادية وإجتماعية.

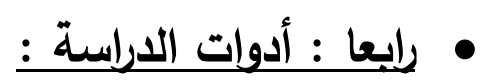

(1) مقياس قلق المستقبل : Future Anxiety ( إعداد زينب محمود شقير ،ه . . r) : (r) مقياس التوافق النفسى (r. (rimensions of Pshchological Adjustment إعداد ( زينب شقير $:\left(r+1 r_{6}\right.$

(r) : البرنامج التدريبى المستخدم لتخفيف قلق المستقبل : ( إعداد الباحثة ) 
وتلخص الباحثة توزيع مراحل البرنامج التدريجى، والهدف منها كما هو موضح في الجدول التالي:

\begin{tabular}{|c|c|c|}
\hline 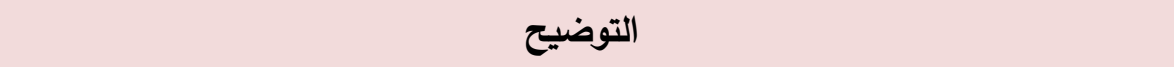 & البيان & r \\
\hline بربامبا في مرحله الإرشادي القائم على التفكير الايجابي لتخفيف قلق المستقبل لدى عينه من المعاقين & العنوان & 1 \\
\hline تخفيف قلق المستقبل لاى عينه من المعاقين بصريا في مرحله المراهقة & 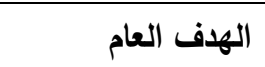 & r \\
\hline 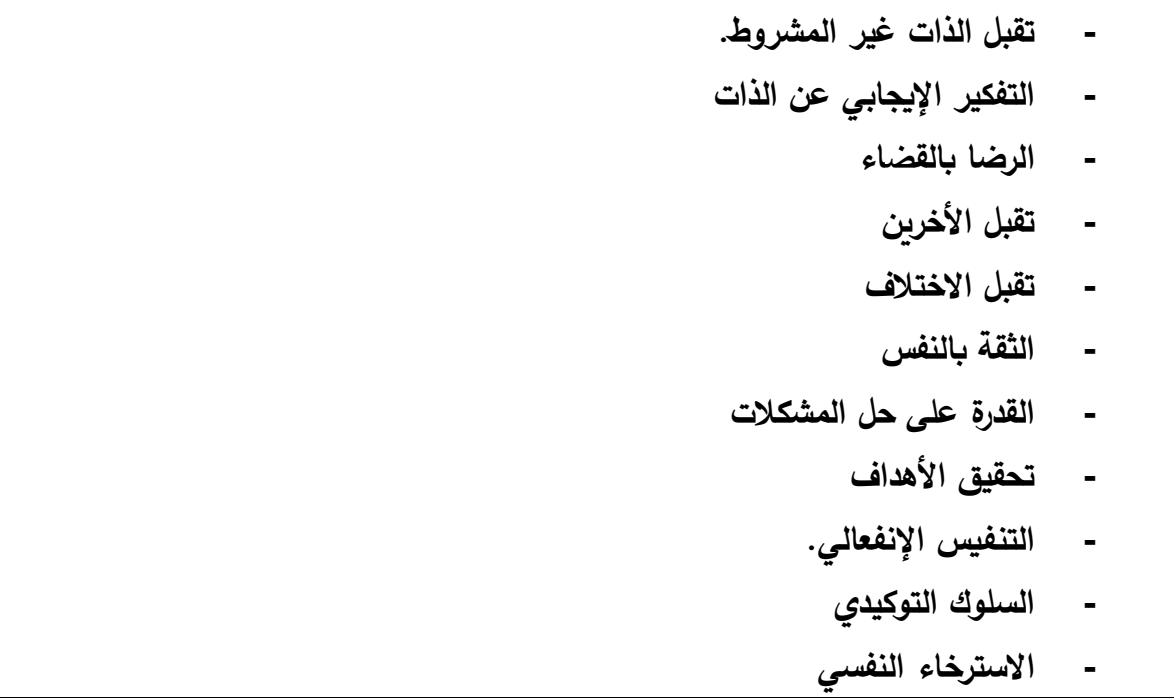 & الأهداف الخاصة & r \\
\hline 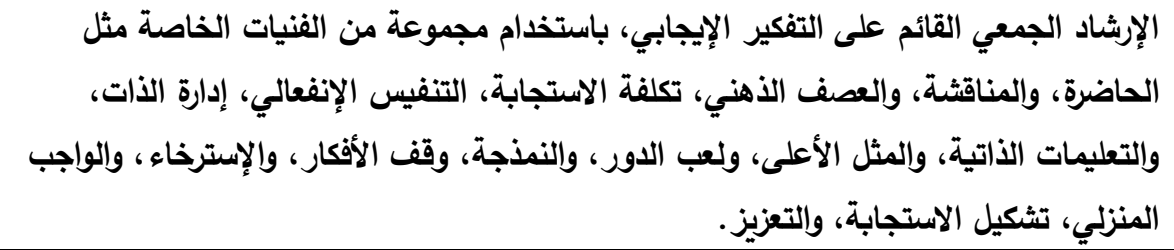 & 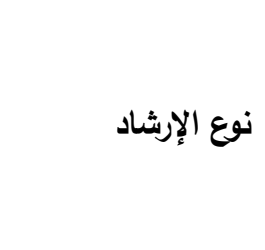 & $\varepsilon$ \\
\hline 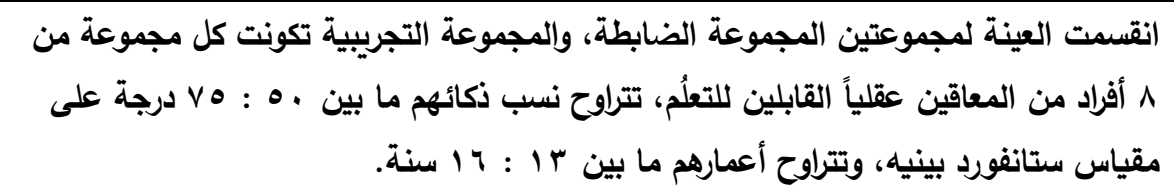 & العينة & • \\
\hline لداخل حجرة ................... بمدرسة النور للمكفوفين بثبين الكوم - محافظة المنوفية، & مكان تنفيذ البرنامج & 9 \\
\hline 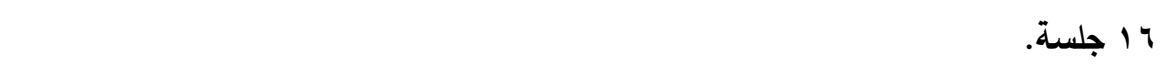 & عدد الجلسات & $v$ \\
\hline يتراوح زمن الجلسة الواحدة ما بين ه ؛ : . دقيقة. & زمن الجلسة & $\wedge$ \\
\hline جا أسابيع بواقع × جلسات أسبوعياً. & مدة البرنامج & 9 \\
\hline 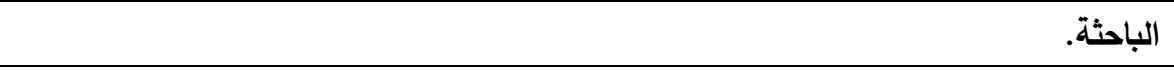 & منفذ البرنامج & 1 . \\
\hline تقييم قبلي - تقييم بعدي - تقييم تتبعي. & تقييم البرنامج & 11 \\
\hline
\end{tabular}


سابعا:الأساليب الإحصائية المستخدمة:

كي تتحقق الباحثة من فروض الدراسة إستخدمت مجموعة من الأساليب الإحصائية تمثلت في : - المتوسطات والانحراف المعياري . - اختبار ويلكوكسون لالالة الفروق بين مجموعتين مترابطتين -

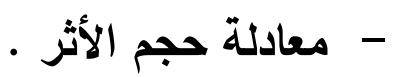

\section{نتائج الاراسةة :}

أظهرت نتائج المعالجة الإحصائية للبيانات عن النتائج الآتية : (1) وجود فرق ذا دلالـة إحصـائية (عند مستوي 1 ( , ·) بين درجات عينـة البحث من المعاقين بصريا في التطبيقين القبلي والبعدي لاختبار التوافق النفسي لصالح التطبيق البعدي ككل ولأبعاده الفرعية.

(Y) وجود فرق ذا دلالـة إحصـائية (عند مستوي l +, · ) بين درجات عينـة البحث من المعاقين بصريا في التطبيقين القبلي والبعدي لاختبار قلق المستقبل لصالح التطبيق البعدي ككل ولأبعاده الفرعية.

(r) عدم وجود فرق ذا دلالة إحصائية (عند مستوي ه . , • ) بين درجات عينة البحث من المعاقين

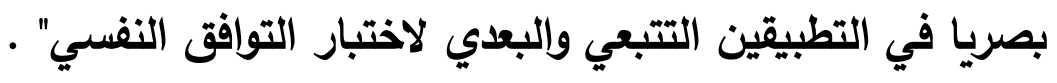
( ) لا يوجد فرق ذا دلالة إحصائية (عند مستوي ه •. . •) بين درجات عينة البحث من المعاقين بصريا في التطبيقين التتبعي والبعدي لاختبـار قلق المستقبل، ممـا يعكس بقـاء أثر البرنـامـج التجرببي. 


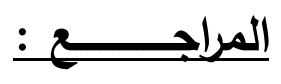

أولاً المراجع العربية :

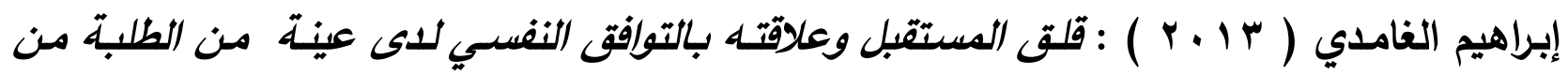

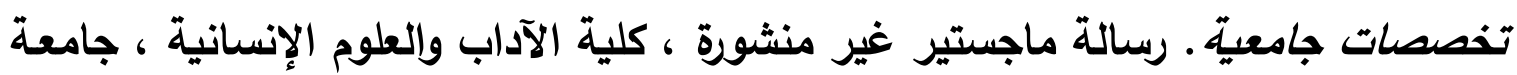

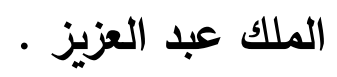

إبراهيم بلكيلاني ( ^ . . r ) : تقدير الذات وعلاقته بقلق المستقبل للى الجالية العربية المقيمـة

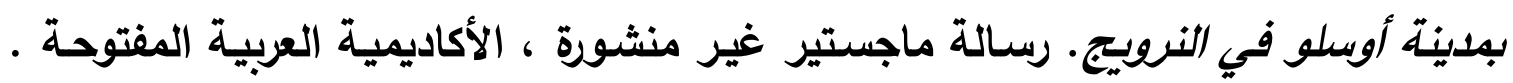
الانمارك . الدائ

إخلاص موسى ( 17 ـ P ) : أثر الإعاقة السمعية والبصرية على التوافق النفسي للى الثخص

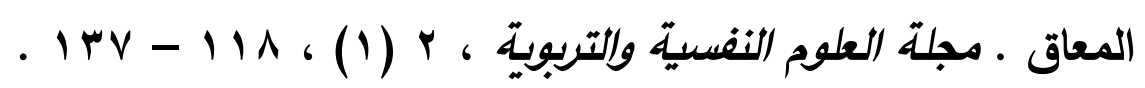

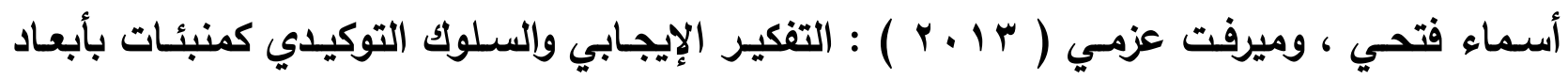
التوافق النفسي لاى عينة من المتفوقين دراسياً من الطلاب الجامعيين ، المجلة المصيرية

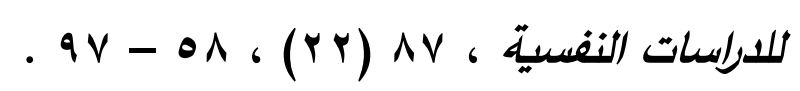

أشرف العريان ( ؟ 1 ـ r ) : التفكير الإيجابي وعلاقته بالتوافق النفسي والذكاء الوجدانسي للى ذوي التأخر الدراسي ، رسالة ماجستير غير منشورة ، كلية الآداب ، جامعة المنصورة.

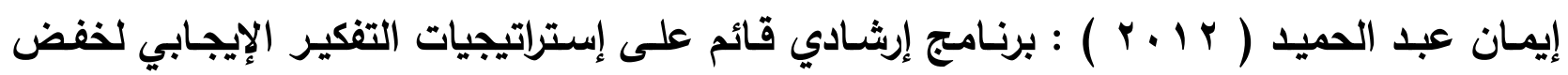

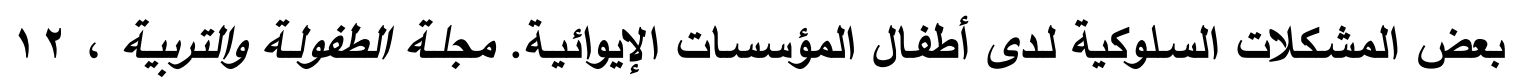

$$
\text { . rq. - r } \leqslant \vee \text { ، }
$$

أيمن عبد العال ( r ا ـ r ) : العلاقة بين ممارسة العلاج المعرفي السلوكي ومستوى قلق المستقبل

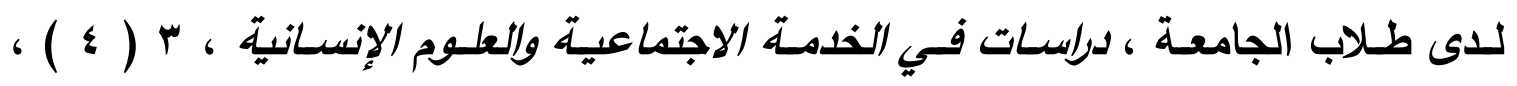

$$
\text { . rE rO- rा r }
$$

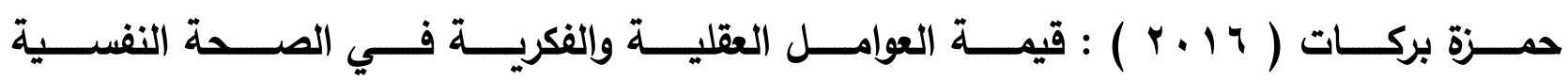

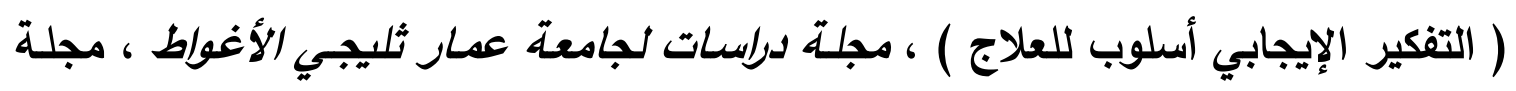

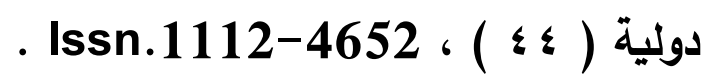




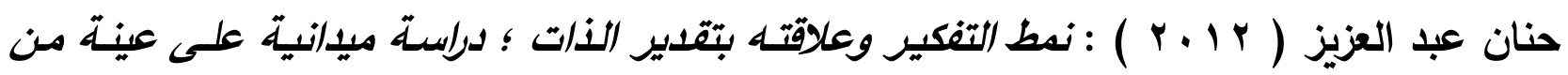

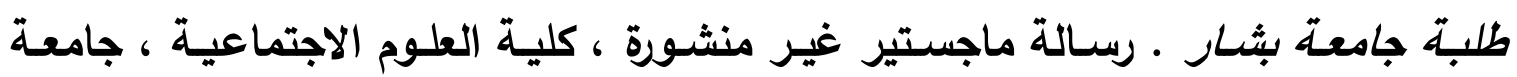

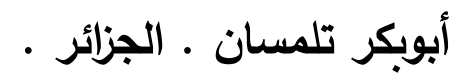

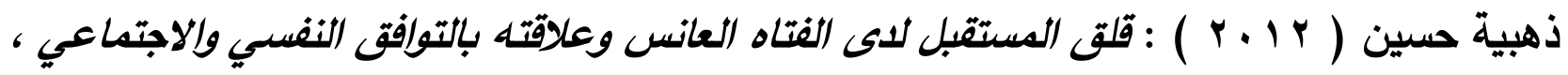

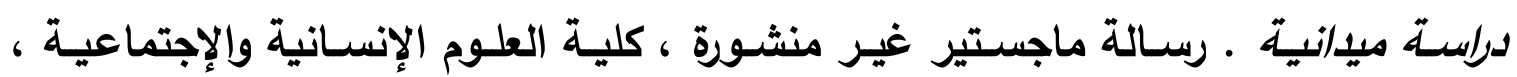

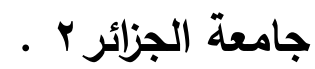

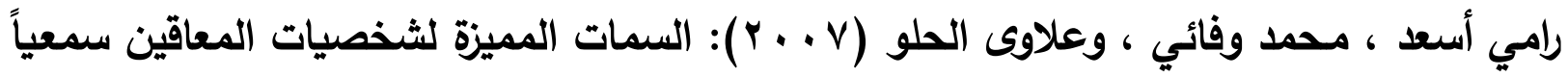
وبصرياص وحركياً في ضوء بعض النتغيرات النيات ـ مجلة الجامعة الإسلامية (سلسلة الدراسات

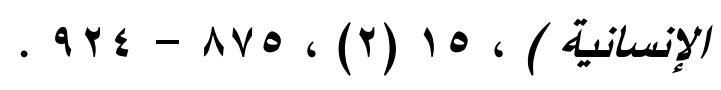

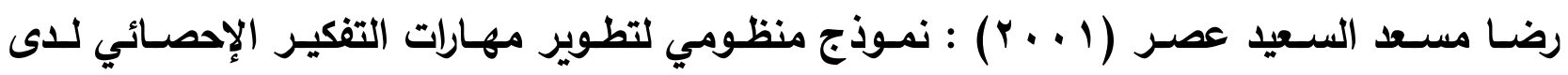

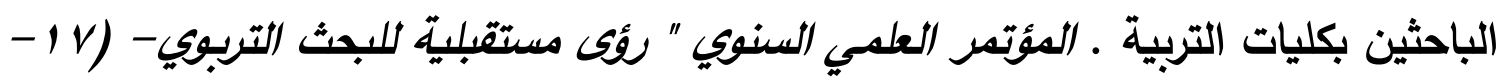

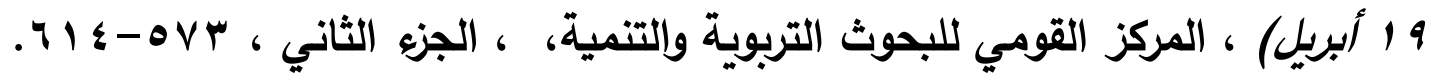

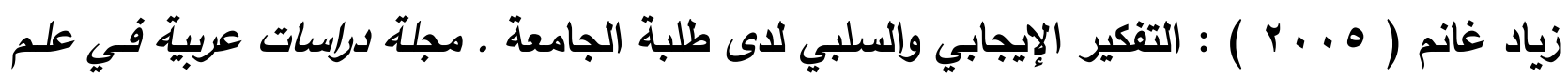

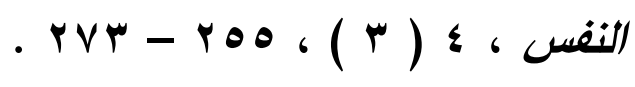

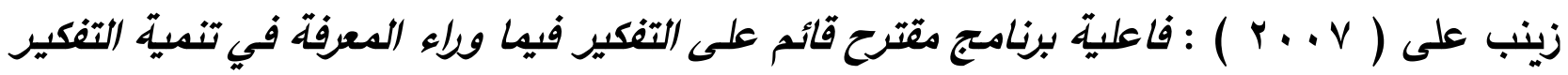

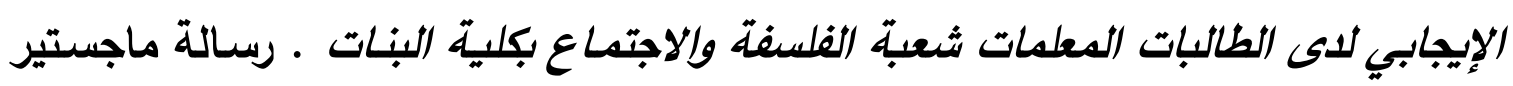
غير منشورة ، كلية البنات جامعة عين شمس .

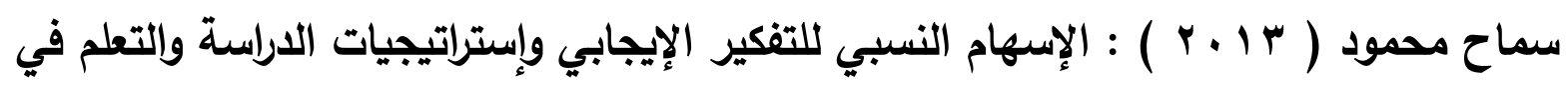

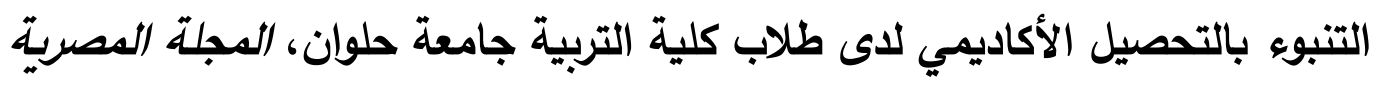

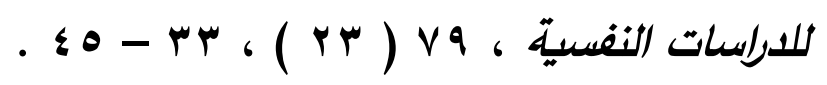

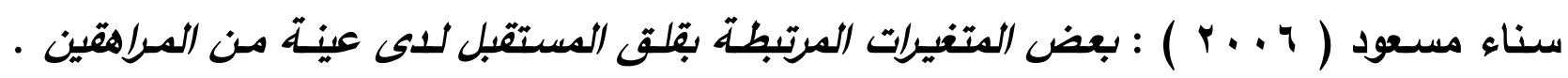

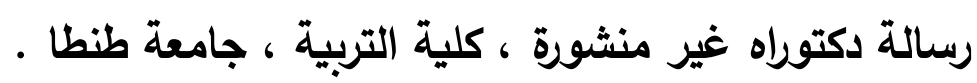

سهام السلاموني ( ؟ ( ب ) ) : فعالية برنامج إرشادي لتنمية التفكير الإيجابي لاى أمهات الأطفال

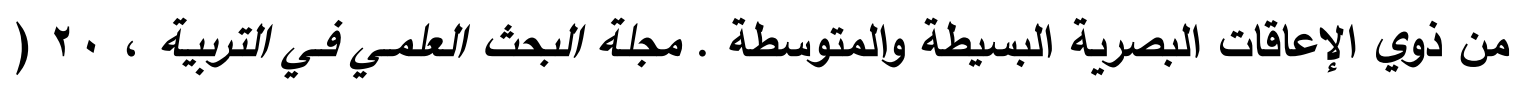

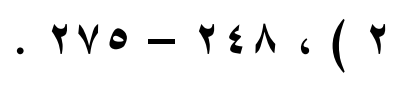


سهلي عبد الصمد ، ومباركي جيلاني ( 10 ب ج ) : التوافق النفسي وعلاقته بقلق المستقبل لاى

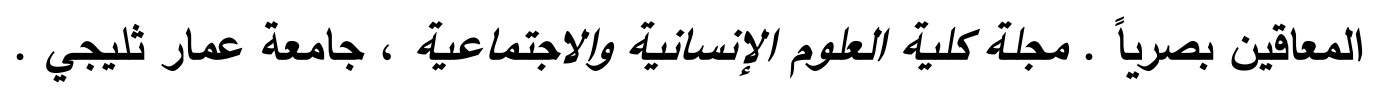

صلاح أحد مراد ( . . ب) : الأساليب الإحصائية في العلوم النفسية و التربوية و الاجتماعية ـ القاهرة : الأنجلو المصرية .

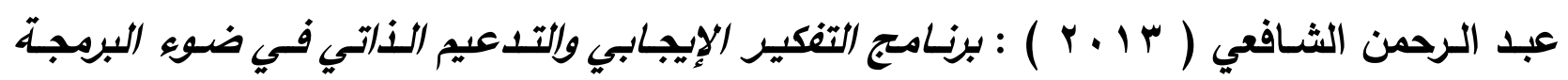

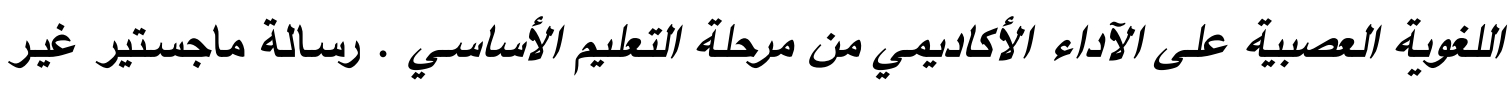

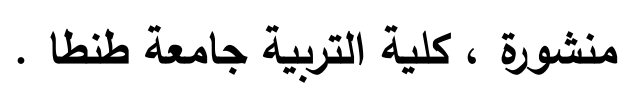

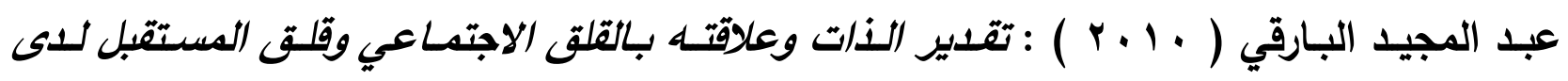

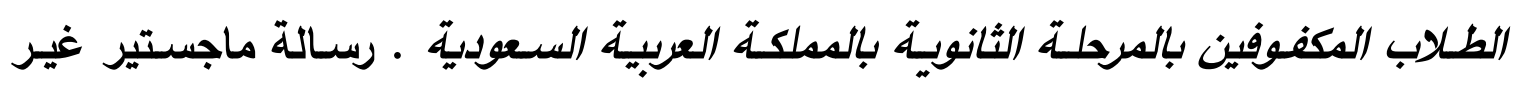
منشورة ، معهد الدراسات التربوية ، القاهرة .

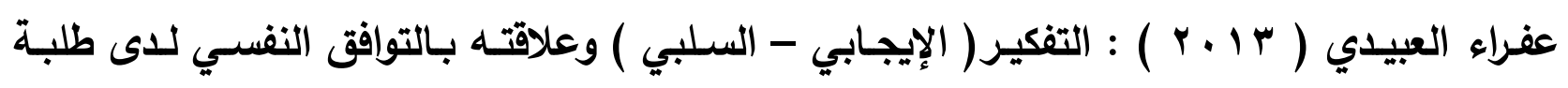

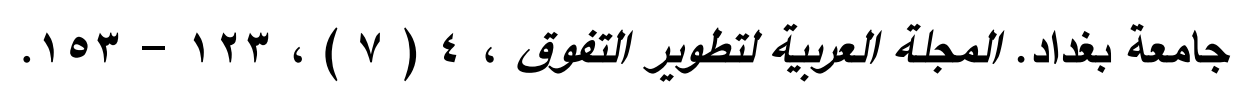

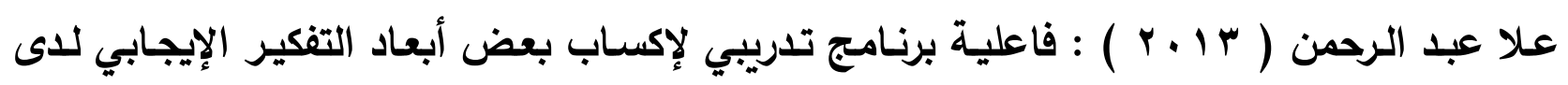

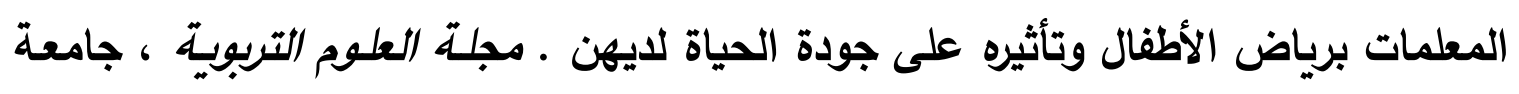

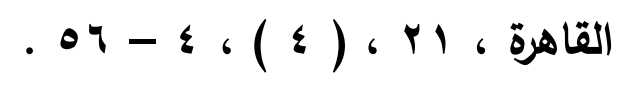

ثانياً : المراجع الأجنيبة :

Andrew, K., Philip, T., Peter, T., Ulrike, S., Kate, D. \&

Simon, T. ( 2005 ). Hopelessness and positive and negative future thinking in Para suicide. British Journal of Clinical Psychology , 44 ( 5 ) , 495 - 504.

Ari, M. ( 2011 ). Analysis of ego identity process of dolescents in terms of attachment styles and gender. procedia social and behavioral sciences, 2 ( 10 ), 744.

Behar, E., Katie, A., Borkovec, A., Michelle, M. (2012). Concreteness of positive, negative, and neutral repetitive thinking about the future. Behavior Therapy, 43 (20), 300 - 312.

Bryan, A . ( 2004 ). Relationships between future orientation: Impulsive sensation seeking and risk behavior among adjudication adolescents. Journal of

Gaber, O. (2016). Level of aspiration, critical thinking and future anxiety as predictors for motivation to learn among asample of students of Najvan university international journal of education and research, 4(2), 41-62. 
Haibach, P., Matthias, O., Wagner, A., Lauren, J., Lieberman, M. (2014). Determinants of gross motor skill performance in children with visual impairments. Research in Developmental Disabilities, 35(20), 2577 -2584.

Haveren, A. ( 2004 ). Levels career decidedness and negative career thinking by athletic status, gender and academic class. Proguest Dissertation Abstracts . No. AAC9963589.

Hogendoorns, S., Prins, P., Vervoort, L., Wolters, L., Nauta, M., Hartman,C., Moorlag, H., De Hann, E. \& Boer, F. ( 2012 ). Positive thinking in anxiety disordered children reconsidered . Journal of Anxiety disorders , 26 ( 1 ), $71-78$.

Hong, C. ( 2012 ). Impacts off book reading club international on enhancing parents positive thinking. Journal of health psychology, 17 (2) , 36 - 72.

Imamoglu, E. \& Guler, A. ( 2007 ). Self - related differences in future time orientation. Journal of applied developmental psychology, 28,515 - 535.

Jean, S. ( 2012 ). Cognitive modification versus therapeutic support for internalizing distress and positive thinking a randomized technique evaluation trial. Cognitive therapy research, 36 ( 1 ), 17 - 32.

Joelle, A. ( 2012 ). The role of positive thinking in social prevention of cancer out comes. Psychology \& Health , 27 (10), 1244 - 1258.

Lopez, F. \& Fuxjager, A. (2012). Self-deception's adaptive value: Effects of positive thinking and the winner effect. Consciousness and Cognition, 21 (2) , 315324.

Lord, K., Tulen, J., Dietrich, A., Sondeijker, F., Roon, A., Oldehinkel, A., Ormel, J., Verhulst, F., Huizink, A. (2010). Reduced autonomic flexibility as a predictor for future anxiety in girls from the general population: The TRAILS study. Psychiatry Research, 2 (10), 187-193.

Mnro, K. ( 2004 ). Optimism: How to avoid negative thinking. www.KaliMunro.com

Ott, S., Roberts, D., Rock, J., Allen, L. \& Kimling, E. (2002). Positive and negative thought disorder and psychopathology in childhood among subjects with adulthood schizophrenia. Schizophrenia Research, 58 (2) , 231-239.

Papadopoulos, K., Anthony, J., Montgomery, A., Chronopoulou, E. (2013). The impact of visual impairments in self-esteem and locus of control. Research in Developmental Disabilities, 34(13), 4565-4570.

Segerstrom, S. (2005). Optimism and immunity: Do positive thoughts always lead to positive effects?. Brain, Behavior, and Immunity, 19 (5) , 195 - 200.

Spinhoven, P., Drost, D., Hemer, B., Brenda, W. \& Penninx, B. (2015). Common rather than unique aspects of repetitive negative thinking are related to depressive and anxiety disorders and symptoms. Journal of anxiety disorders, 33(15) , 45-52 . 
Stoeber, J. \& Corr, P. (2017). Perfectionism, personality, and future-directed thinking: Further insights From revised Reinforcement Sensitivity Theory. Personality and Individual Differences, 105 (2017), 78-83.

Trick, L., Watkins, E., Windeatt, S. \& Dickens, C. (2016). The association of preservative negative thinking with depression, anxiety and emotional distress in people with long term conditions: A systematic review. Journal of Psychosomatic Research, 91(16), 89-101.

Wong, S. ( 2012 ). Negative thinking versus positive thinking in a Singaporean student sample: Relationships with psychological well - being and psychological maladjustment. learning and individual differences, 22 ( 1 ), $76-82$.

Zaleski, Z. (1996). Future anxiety: Concept, measurement, and preliminary research. Personal Individual Differences, 2(21), 165-174 . 